\title{
Arginine-dependent immune responses
}

\author{
Adrià-Arnau Martí i Líndez ${ }^{1}$ [D $\cdot$ Walter Reith ${ }^{1}$
}

Received: 16 November 2020 / Revised: 23 March 2021 / Accepted: 29 March 2021 / Published online: 26 May 2021

(c) The Author(s) 2021

\begin{abstract}
A growing body of evidence indicates that, over the course of evolution of the immune system, arginine has been selected as a node for the regulation of immune responses. An appropriate supply of arginine has long been associated with the improvement of immune responses. In addition to being a building block for protein synthesis, arginine serves as a substrate for distinct metabolic pathways that profoundly affect immune cell biology; especially macrophage, dendritic cell and T cell immunobiology. Arginine availability, synthesis, and catabolism are highly interrelated aspects of immune responses and their fine-tuning can dictate divergent pro-inflammatory or anti-inflammatory immune outcomes. Here, we review the organismal pathways of arginine metabolism in humans and rodents, as essential modulators of the availability of this semi-essential amino acid for immune cells. We subsequently review well-established and novel findings on the functional impact of arginine biosynthetic and catabolic pathways on the main immune cell lineages. Finally, as arginine has emerged as a molecule impacting on a plethora of immune functions, we integrate key notions on how the disruption or perversion of arginine metabolism is implicated in pathologies ranging from infectious diseases to autoimmunity and cancer.
\end{abstract}

Keywords Arginine metabolism · Nitric oxide synthase $\cdot$ Arginase $\cdot$ Immunity $\cdot$ Immunometabolism $\cdot$ Arginase 2 . Arginase $1 \cdot$ NOS

\section{Abbreviations}

AKT Protein kinase B

AP-1 Activator protein 1

APRIL A proliferation-inducing ligand

$\mathrm{BH}_{4} \quad$ Tetrahydrobiopterin

$\mathrm{C} / \mathrm{EBP} \beta \quad$ CCAAT-enhancer-binding protein $\beta$

cAMP Cyclic adenosine monophosphate

eIF2 $\alpha \quad$ Eukaryotic translation initiation factor 2A

ERK Extracellular signal-regulated kinase

FAD Flavin adenine dinucleotide

FMN Flavin mononucleotide

GM-CSF Granulocyte-macrophage colony-stimulating factor

IFN Interferon

IL Interleukin

IL-2R Interleukin 2 receptor

IRF1 Interferon regulatory factor 1

ITAM Immunoreceptor tyrosine-based activation motif

Adrià-Arnau Martí i Líndez

adria-arnau.marti@unige.ch

1 Department of Pathology and Immunology, Faculty of Medicine, University of Geneva, Geneva, Switzerland
L-NAME $\quad$ L- $\mathrm{N}^{\mathrm{G}}-\mathrm{Nitroarginine}$ methyl ester

L-NMMA L- $\mathrm{N}^{\mathrm{G}}$-Monomethyl arginine acetate

MHC Major histocompatibility complex

NADPH Nicotinamide adenine dinucleotide phosphate

NF- $\kappa$ B Nuclear factor kappa-light-chain-enhancer of activated B cells

pMHC-I Cognate peptide and MHC-I molecule complex

PD-1 Programmed cell death protein 1

PGE2 Prostaglandin $\mathrm{E}_{2}$

PHA Phytohemagglutinin

ROS Reactive oxygen species

STAT Signal transducer and activator of transcription

TGF- $\beta \quad$ Transforming growth factor-beta

Th Thelper

\section{Introduction}

The restriction of amino acid availability is an evolutionarily conserved strategy for controlling cellular functions of both the host and pathogens [1]. One such amino acid is arginine, a proteinogenic $\alpha$-amino acid that is encrypted 
in mRNA molecules for protein synthesis. As a free amino acid, arginine serves as the substrate for different nitrogencontaining compounds. In ureotelic animals, arginine is a key substrate for ammonia detoxification via the urea cycle. Free arginine also serves as a substrate for other biologically active compounds. Being a core metabolic module, arginine metabolism directly and indirectly participates in a plethora of biological phenomena, such as vasodilation, calcium release, regeneration of adenosine triphosphate, neurotransmission, cell proliferation, and, most notably, immunity [2, 3]. Beyond constituting a mere nutrient, arginine metabolism has recently emerged as a critical pathway for controlling immune cell function, including metabolically demanding activated $\mathrm{T}$ cells $[4,5]$. Certain pathogens and malignant cells exploit arginine's relevance for the immune system and co-opt arginine metabolism to impede host immune responses [6].

\section{Arginine: a multifaceted amino acid}

Arginine is defined as a semi-essential amino acid, because under certain conditions, such as growth during infancy, pregnancy, severe immune challenge, or burn injuries [7, 8]; humans require a supplemental intake of dietary arginine. Human adults are able to synthesize arginine from glutamine, glutamate, and proline $[9,10]$, and dietary amino acids represent the major influx of circulating arginine. However, endogenous arginine synthesis does not suffice to compensate for dietary arginine insufficiency $[11,12]$. The dependence on dietary arginine provision during periods of increased demand for this amino acid consequently accounts for the conditional essentiality of arginine [13].

Arginine was first isolated in 1886 [14] and identified as a proteinogenic amino acid soon afterwards [15]. In 1932, Krebs and Henseleit first postulated the existence of the urea cycle [16], pioneering the identification of a prominent role of L-arginine (hereafter arginine) in human physiology: the detoxification of neurotoxic ammonia [17]. Besides protein anabolism and ammonia detoxification, arginine regulates a plethora of biological processes, such as vasodilation, calcium signaling, regeneration of adenosine triphosphate, neurotransmission, cell proliferation, and immunity $[2,3]$.

Arginine serves as a precursor for numerous biologically active compounds: nitric oxide (NO), ornithine, proline and polyamines, creatine and hence phosphocreatine, and agmatine. Arginine also regulates its synthesis via allosteric activation of the synthesis of $\mathrm{N}$-acetylglutamate [18], a cofactor subsequently required for glutamine metabolization into arginine. Moreover, infused arginine-but not enteral arginine-acts as a secretagogue, stimulating the secretion of anabolic hormones, such as insulin, glucagon, prolactin, somatostatin, pancreatic polypeptide from the pancreas, and adrenal catecholamines [19-21]. In support of its endocrine effects, arginine transport into pancreatic beta-cells leads to membrane depolarization and electrochemical stimulation of beta-cells [19].

The $\mathrm{p} K_{\mathrm{a}}$ value of $13.8 \pm 0.1$ of arginine's guanidinium group [22] implies that the arginine side chain remains protonated throughout all physiologic conditions, therefore, operating as a positively charged, basic amino acid. Moreover, it has been hypothesized that the positively charged guanidium group interferes with the incorporation of arginine into the hydrophobic interior of proteins, exerting an evolutionary selective pressure against the incorporation of arginine into bigger and more complex proteins [23]. Paradoxically, although the genetic code comprises six codons for arginine incorporation into proteins, the average content of arginine in animal proteins is markedly lower than what would be expected from the theoretical frequency of codons associated to it [24]. This negative bias against arginine incorporation into proteins could conceal a repurposing of arginine beyond structural functions, implying the evolution of free-arginine usage towards regulatory functions. In this respect, a growing body of evidence indicates that over the course of immune system evolution, arginine has been selected as a metabolic node for the regulation of immune responses [4].

\section{Potential of arginine as an immune enhancer}

Early studies established that arginine availability has critical roles in the immune system. Detrimental effects of arginine starvation on human $\mathrm{T}$ lymphocytes were first described in 1968 by the establishment of a causal relationship between arginine depletion and impaired in vitro activation of lymphocytes stimulated with phytohemagglutinin [25]. Subsequent in vitro studies demonstrated that human Burkitt lymphoma B cells also require adequate arginine concentrations for their proliferation and maturation [26]. Animal experimentation revealed that arginine administration prevents thymic involution after surgery and increases lymphocyte counts [27, 28]. Moreover, it also became clinically apparent that there is an arginine requirement for proper wound healing [28-30].

Pursuant to such observations of arginine's immunostimulatory effects, dietary arginine supplementation gained attention, with the aim of creating so-called immune-enhancing diets (IED) [31-33]. These diets included between two and six times greater arginine contents than normal diets, as well as $n-3$ fatty acids, nucleotides, and other micronutrients with alleged immunostimulatory effects. Numerous IED trials conducted in a variety of patient populations have unfortunately resulted in mixed outcomes [32]. For instance, highrisk surgery patients benefited from IED diets by exhibiting 
reduced infections, and trauma patients exhibited an increase in markers of enhanced immunity [34-36]. Conversely, IED diets failed to show any benefit in critically ill non-surgical patients, with controversial effects in sepsis patients [31-33, 37], for which arginine supplementation remains of questionable value or is even counter-indicated [38, 39]. Determining whether arginine metabolism regulates immune cell functions in specific diseases will undoubtably foster the development of personalized therapeutic interventions in pathologies, where modulating arginine metabolism proves to be beneficial.

\section{Dietary arginine intake and organismal-level arginine synthesis}

The turnover of circulating arginine in human adults is rapid, with half-life measurements ranging from 41.6 to $79.5 \mathrm{~min}$ depending on the administration route and arginine dose [40]. The plasma arginine concentration ranges from 6.7 to $81.6 \mu \mathrm{mol} / \mathrm{L}$ in young humans and from 7.8 to $113.7 \mu \mathrm{mol} / \mathrm{L}$ in the elderly [41, 42], and five main factors regulate its plasmatic concentration: dietary arginine intake, endogenous arginine synthesis, arginine catabolism, hepatic urea excretion, and protein turnover. Although both the diet and biosynthesis significantly contribute to arginine fluxes, protein turnover remains the major contributor to the circulating pool of free arginine [43]. Modern western diets provide, on average, a daily intake of 3-6 $\mathrm{g}$ of arginine [44, 45]. Orally ingested arginine is absorbed in the jejunum and in the ileum via a specific amino acid transporter, classically known as the $\mathrm{y}^{+}$transporter, which mediates uptake of the basic amino acids lysine, ornithine, histidine, and arginine [46, 47]. In human adults, however, arginase activity in the intestinal mucosa degrades approximately $40 \%$ of the arginine absorbed in the small intestine [48].

The endogenous synthesis of arginine yields a daily production of 15-20 g of arginine [49]. However, arginine dietary supply does not alter its synthesis rates, and increased arginine synthesis is not used to counterbalance a reduction in dietary intake [12]. Although hepatocytes synthesize arginine efficiently, urea cycle enzymes are organized in a metabolon that channels de novo synthesized arginine to arginase-mediated hydrolysis [50, 51], thus resulting in little to no net synthesis of arginine in the liver. Furthermore, only about 5\% of the urea produced by the liver derives from plasma arginine [52]. The liver is, therefore, regarded as an arginine-depleted organ, in which arginine concentrations $(0.03-0.10 \mu \mathrm{mol} / \mathrm{L})$ are considerably lower than those of other amino acids $(0.5-10.0 \mu \mathrm{mol} / \mathrm{L})$ [53]. This also reflects strict segregation between hepatic and circulating arginine pools.

Unlike arginine synthesis in the urea cycle, most de novo arginine synthesis entails an inter-organ pathway: the intestinal-renal axis [54, 55] (Fig. 1). In a first step, enteral glutamine and glutamate, as well as circulating glutamine, are taken up by the small intestine and finally converted to citrulline in a series of reactions initiated by $\mathrm{L}-\Delta^{1}$-pyrroline-5-carboxylate (P5C) synthetase. Citrulline is subsequently released by the intestines into the bloodstream, with an efficient bypass of the first-pass metabolism. Once in the systemic circulation, virtually, all fluxes of citrulline in the plasma feed into de novo arginine synthesis by the kidneys, being up taken at the proximal tubule of the nephron [56-58]. In the kidney, argininosuccinate synthase (ASS1) converts citrulline to argininosuccinate, and subsequently, argininosuccinate lyase (ASL) converts it to arginine (Fig. 1), which ultimately reenters circulation in the bloodstream. The kidney is, therefore, the primary organ responsible for maintaining circulating arginine levels $[54,55]$. In certain conditions, macrophages can also regenerate arginine pools thanks to the reconversion of citrulline to arginine via ASS1 and ASL [59, 60]. Importantly, however, not all cell types concomitantly express all the enzymes required for de novo arginine synthesis; hence, certain cell types, notably cells of the immune system, depend on circulating supplies of arginine or its immediate precursors.

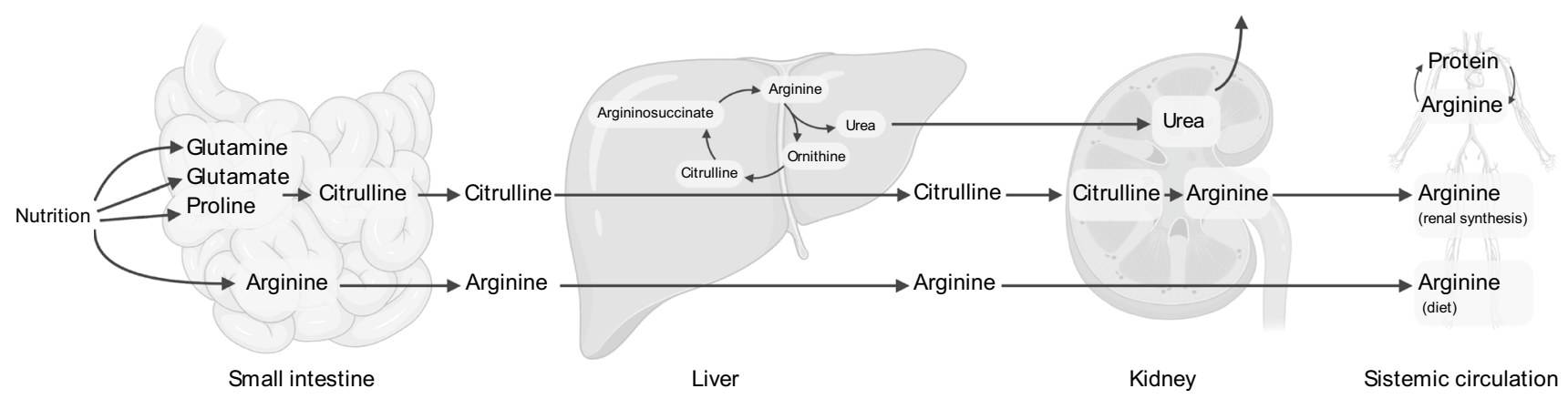

Fig. 1 Inter-organ arginine metabolism and the intestinal renal arginine synthesis axis 


\section{Intracellular arginine metabolism}

\section{Cellular uptake}

Intracellular arginine concentrations are considerably greater than those in the extracellular microenvironment or in the blood. Plasma arginine concentrations in healthy adults oscillate between 0.05 and $0.20 \mathrm{mmol} / \mathrm{L}$, while intracellular arginine concentrations range from 0.10 up to $1.00 \mathrm{mmol} / \mathrm{L}$ depending on the cell type [61-63]. Lipid membranes are not permeable to the positively charged arginine molecule, which prevents its free diffusion and permits significant compartmentalization of different arginine pools [64]. The build-up of intracellular arginine pools, therefore, entails the involvement of transporter systems.

Cellular uptake of arginine involves several different amino acid transport systems, including mainly the cationic amino acid transporters CAT-1 and CAT-2 [65, 66], with minor involvement of the LAT- 1 and LAT- 2 proteins and the $\mathrm{B}^{\mathrm{o}},+$ and $\mathrm{b}^{\mathrm{o}},+$ systems $[67,68]$. The principal arginine transporter in most cell types is CAT-1, which translocates arginine in a $\mathrm{Na}^{+}$-independent manner and can be transstimulated by other cationic amino acids [69]. Different peripheral cells express CAT-1, such as macrophages, platelets, endothelial cells, and vascular smooth muscle cells. The CAT-2 transporter exists in two isoforms: CAT-2A and CAT-2B, of which only the latter exhibits high affinity for arginine and is expressed in macrophages and $\mathrm{T}$ cells [68, 70]. Notably, the CAT-1 transporter can be competitively inhibited by lysine, ornithine and canavanine, as well as by certain inhibitors of the arginine-metabolizing enzyme nitric oxide synthase 2 (NOS2), such as L-NMMA and L-NIO [71-73]. Therefore, certain NOS2-inhibiting pharmacologic interventions can interfere with the availability of arginine for other arginine-metabolizing enzymes.

In several biological systems, the induction of arginase and NOS2 enzymes is concomitant with the upregulation of arginine transporter expression [74-76]. Moreover, cytokines, such as interferon gamma (IFN- $\gamma$ ) and tumor necrosis factor $\alpha$ (TNF- $\alpha$ ), stimulate the activity of both arginine transporters and arginine-metabolizing enzymes [77, 78]. These observations suggest that these proteins constitute a functional unit of the response to metabolic demands imposed by immune challenges.

Although arginine transporters in the plasma membrane are well characterized, knowledge about the transport of arginine through mitochondrial membranes remains quite limited. Recent reports demonstrate that the SLC25A29 gene encodes a mitochondrial transporter of basic amino acids, amongst them arginine [79]. However, mechanisms mediating arginine trafficking into the mitochondria of immune cells remain unexplored.

\section{Catabolism}

The largest fraction of the circulating free-arginine flux is expended for protein synthesis - via loading of arginine onto arginyl-tRNAs by arginyl-tRNA synthetases [80]. Arginyl-tRNAs also catalyze the conjugation of arginine to the N-termini of proteins and their consequent degradation by the ubiquitin-dependent proteolytic pathway [81]. Strikingly, ammonia detoxification only consumes a very minor portion of the arginine flux. Besides protein turnover and ammonia detoxification, a number of distinct metabolic pathways catabolize the remainder proportion of circulating arginine, thus serving different functions which, frequently, are concomitantly active in the same cell.

\section{Arginases}

The arginase pathway leads to arginine hydrolysis and the consequent production of urea and ornithine. Urea, a toxic water-soluble metabolite, is efficiently excreted by the kidneys. Ornithine can be further metabolized by ornithine aminotransferase (OAT) and other enzymes to generate proline or glutamate or, alternatively, by ornithine decarboxylase (ODC) to generate putrescine and downstream polyamine metabolites [1, 43] (Fig. 2). Another prominent fate of arginase-derived ornithine is to feed the urea cycle: ornithine can be subsequently converted to citrulline by ornithine carbamoyltransferase (ODC) and, via arginine-synthesizing enzymes ASS1 and ASL, citrulline is used to regenerate arginine and hence iterate the next cycle of the urea cycle (Fig. 2).

Mammals express two arginase isoforms (Arg1 and $\operatorname{Arg} 2)$ encoded by different genes. Although there is strict conservation of the catalytic site [82], the human isoforms exhibit only 58\% amino acid homology. The isoforms differ in their tissue distribution and subcellular localization. Whereas Arg1 does not contain any targeting sequence, and is thus located in the cytosol, both human and mouse Arg2 have an $\mathrm{N}$-terminal mitochondrial targeting sequence that is cleaved during protein maturation [82, 83]. In ureotelic organisms, only the Arg1 isoform is highly expressed in the liver, where it ensures that the arginase activity required for the urea cycle. Outside of the liver, Arg1 expression circumscribes to discrete cell types and is under transcriptional control by cytokines. On the contrary, Arg2 presents a more ubiquitous and constitutive expression pattern, independent of regulation by cytokines. Phylogenetic analysis suggest that Arg2 is the ancestral gene from which Arg1 arose via a duplication event during the evolution of vertebrates to terrestrial adaptation and the emergence of a need for water-soluble excretion of nitrogen [84]. 


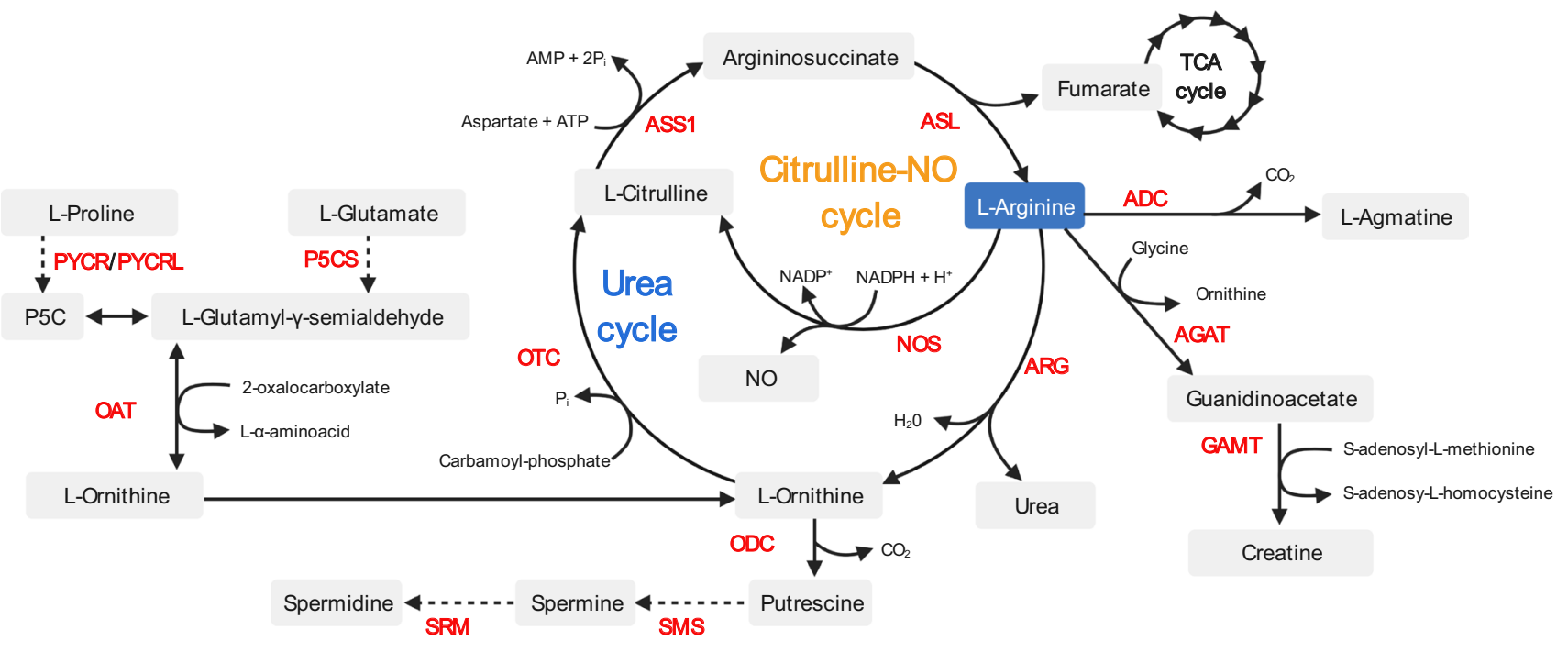

Fig. 2 Overview of pathways involved in arginine metabolism. Abbreviations: $A D C$ arginine decarboxylase, $A G A T$ arginine:glycine amidinotransferase, GAMT guanidinoacetate $N$-methyltransferase $A R G$ arginase, NOS nitric oxide synthase, ASL argininosuccinate lyase, $O D C$ ornithine decarboxylase, ASS1 argininosuccinate syn-

\section{Nitric oxide synthases}

Nitric oxide synthases (NOS) catabolize arginine, resulting in the generation of nitric oxide (NO) and citrulline. Notably, arginine is the sole substrate used for NO synthesis [85]. Mammals have three distinct NOS isoforms (NOS1, NOS2, and NOS3) encoded by different genes. All three isoforms require $\mathrm{BH}_{4}$, haem, $\mathrm{FAD}$, and $\mathrm{FMN}$ as cofactors for maximal activity, but differ with respect to their intracellular localization, kinetic properties, inhibitor sensitivity, and expression patterns. NOS 1 and NOS3 are constitutively expressed in neuronal and endothelial cells, respectively. In endothelial cells, NO serves as a signaling molecule for inducing vasodilation: endothelium-derived NO regulates smooth muscle diastole, thereby increasing blood flow. It also inhibits platelet aggregation [86] and leukocyte aggregation [87]. NOS2 is the prevalent isoform in immune cells, where it is not constitutively expressed, but is strongly induced by lipopolysaccharide (LPS) and inflammatory cytokines: it is hence known as inducible NOS or iNOS. Once expressed, NOS2 is constitutively active and its activity only depends on regulation by its substrate - arginine promotes dimerization of catalytically active NOS 2 dimers-or cofactor availability [88].

NOS2 is most often implicated in the production of NO during pro-inflammatory responses. NO can react with other oxygen species to generate nitrite and nitrate as well as other highly cytotoxic reactive nitrogen species (RNS). The biological roles of NO are multiple and its synthesis during inflammatory conditions can entail both beneficial, thase 1, OTC ornithine carbamoyltransferase, SMS spermine synthase, SRM spermidine synthase, P5CS delta-1-pyrroline-5-carboxylate synthase, PYCR pyrroline-5-carboxylate reductase, PYCRL pyrroline-5-carboxylate reductase-like, $O A T$ ornithine aminotransferase

e.g., liver protection in LPS-treated rats [89], and detrimental consequences, e.g., aggravated ulcerative colitis and mucosal destruction [90]. NO is also a potent cytostatic and cytotoxic molecule that can inhibit cell growth or kill cells in an unspecific way. For instance, high local concentrations of NO can damage cells by condensing amino acid and/or thiol groups, activating the p53 pathway [91], or inducing cell necrosis caused by the peroxynitrite-oxidizing radical [92]. Likewise, low NO concentrations can also impair specific cellular functions. For example, Complex IV of the respiratory electron transport chain is highly sensitive to NO inhibition [93]. Therefore, the complex and diverse consequences of NO synthesis require regulatory mechanisms that unleash NOS2 activity only under precise conditions.

Paradoxically, NO synthesis rates depend on arginine concentration, even though the low $K_{\mathrm{m}}$ of NOS enzymes implies that these enzymes should be saturated at all physiological arginine concentrations [94]. This irreconciled observation is known as "the arginine paradox" and numerous theories have aimed at disentangling this conundrum, such as the existence of non-interchangeable intracellular pools of arginine [64] or general control nonderepressible 2 (GCN-2)-mediated transcriptional control of NOS2 by arginine availability [95]. An additional mechanism regulating NOS activity involves substrate competition with arginase enzymes: although $K_{\mathrm{m}}$ of ARG1 and ARG2 are 3000-fold higher than that of NOS2, $V_{\max }$ of arginases are 1000-fold greater than that of NOS2. Hence, arginases and NOS2 catabolize arginine at similar rates [96] and effectively compete with each other for their substrate when co-expressed [43, 
97]. A number of additional mechanisms also contribute to the crosstalk between the arginase and NOS2 pathways. First, the intermediate subproduct $N$ - $\omega$-hydroxy-L-arginine of the reaction catalyzed by NOS2 is an inhibitor of arginase activity [98]. Second, arginine availability controls the translation of NOS2, which can, therefore, be modulated by arginase activity [95]. Last, arginine depletion by arginase promotes the uncoupling of NOS2, which impedes NO synthesis and promotes the generation of RNS (reviewed below).

\section{Creatine pathway}

In a similar vein as for NO production, arginine is the only amino acid that provides the amidino group for creatine synthesis [43]. In this pathway, arginine serves as a donor for the transfer of the amidino group to a glycine backbone. L-arginine:glycine amidinotransferases (AGAT) catalyze this reaction, to generate ornithine and guanidinoacetic acid. The latter is subsequently methylated by $S$-adenosyl-L-methionine: $N$-guanidinoacetate methyltransferases (GAMT), to ultimately produce creatine and $S$-adenosylhomocysteine. Although systemic creatine synthesis involves an inter-organ pathway [7, 99], the expression of creatinesynthesizing AGAT and GAMT activity has been documented in human and rat spleens, respectively [99]. Of note, the creatine kinase enzyme can reversibly phosphorylate creatine to phosphocreatine, using adenosine triphosphate (ATP) as phosphate donor or acceptor. Creatine thus serves as major energy storage and transport molecule, having major implications for the energy-demanding biosynthetic processes performed by immune cells.

\section{Agmatine and polyamine pathways}

Plants and bacteria-including human microbiota species-express arginine decarboxylase (ADC) enzymes that catabolize arginine to agmatine and $\mathrm{CO}_{2}$. The presence of an ADC gene in humans is controversial [100], although agmatine synthesis has been detected in the small intestine, brain, kidney, liver and adrenal tissue, as well as in macrophages [101-104]. However, the direct effects of agmatine on immune cells remain unstudied, and it remains unclear whether immune cells synthesize agmatine via arginine catabolism or they import it from exogenous sources, such as the diet and microbiota synthesis. Nevertheless, agmatine catabolism converges with the arginase pathway, as it results in the synthesis of ornithine. The resulting ornithine can be further catabolized to generate different polyamine metabolites, which are well-known stimulators of cell growth and differentiation $[1,43]$.

\section{Arginine metabolism in immune cells}

\section{Macrophages}

Canonical classifications divide activated macrophages into two functional subsets: M1 or classically activated and M2 or alternatively activated $[105,106]$. These two subsets catabolize arginine in a divergent manner-via predominant NOS2 or ARG1 activity, respectively-and the functional consequences associated with the dominant pathway are typical classifiers for each subset $[1,107,108]$. However, basing the classification of activated macrophages on the polarization of arginine metabolism is an oversimplification of the complex immunobiology of activated macrophages, as they may express neither ARG1 nor NOS2 [109], or use both pathways concomitantly, as observed in murine macrophages after LPS stimulation [110]. The expression of Arg2 in macrophages may also affect arginine catabolism $[111,112]$. However, the importance of this contribution is ill-defined, as ARG2 expression is independent of cytokines that affect macrophage function and ARG2 is not the predominantly active arginase in these cells $[113,114]$. The roles of creatine and agmatine synthesis in macrophages also remain poorly defined. However, recent studies indicate that the uptake of creatine in macrophages promotes IL-4 and STAT6 induces ARG1 expression, and the suppression of M1 polarisation [115]. Similarly, agmatine promotes ARG1 expression in vivo [116] and suppression of the M1 phenotype in vitro $[117,118]$.

\section{M1 or classically activated macrophages}

M1 macrophages predominantly catabolize arginine via NOS2. Th1 cytokines drive M1 activation and induce NOS2 activity while inhibiting Th2-driven ARG1 expression [1]. The synthesis of NO endows M1 macrophages with proinflammatory and microbicidal properties, and renders them proficient for cytotoxic clearing of intracellular pathogens and malignant cells [119-122]. In these macrophages, Th1 inflammatory cytokines, such as IFN- $\gamma$, IFN- $\alpha$, IFN- $\beta$, and IL-1, drive the activation of transcription factors, such as NF- $\kappa$ B, AP-1, IRF1, and STAT1 [123-126]. The transcriptional program activated by these factors induces NOS2 expression [127] and co-expression of arginine transporters $[71,128]$ and enzymes implicated in the synthesis of NOS2 cofactors [129-132]. However, intense NOS2 activity could limit arginine availability and, therefore, impair NO synthesis. To circumvent arginine scarcity, citrulline can replenish the intracellular arginine pool, as stimuli, such as IFN- $\gamma$ and Toll-like receptor (TLR), agonists also induce ASS1 expression. ASS1, coupled to constitutively expressed ASL, allows the recycling of citrulline into argininosuccinate and 
subsequent de novo arginine synthesis. The importance of citrulline recycling - known as the citrulline-NO cycle-is manifested in Ass $1^{-/-}$macrophages, which fail to control mycobacterial infections [133].

\section{M2 or alternatively activated macrophages}

M2 macrophages predominantly catabolize arginine via ARG1. In this instance, the Th2 cytokines IL-4 and IL-13 promote Arg1 upregulation via binding of STAT6, together with STAT3 and C/EBP $\beta$, to an enhancer in the Arg1 locus [134-136]. Likewise, Arg 1 expression can also be induced via autocrine cytokines produced by mycobacteria-infected macrophages, such as IL-10, IL-6, and GM-CSF [137], as well as by other soluble factors, such as TGF- $\beta$, PGE2, catecholamines, cAMP, and TLR agonists [138-140]. The functions of M2 macrophages are, in part, mediated by the induction of ornithine, proline and polyamines synthesis [141, 142]; pathways that enable mechanisms essential for regulating humoral immunity, anti-parasitic responses, allergy, and fibrosis and wound repair processes [143]. For instance, in vitro pharmacologic inhibition of Arg 1 and macrophage-specific deletion of Arg1 have indicated that Arg1expressing macrophages are critical for matrix deposition and wound healing [144]. A potential explanation of such effects is that arginase activity potentiates collagen production via increased proline synthesis $[145,146]$. In line with this notion, the metabolism of arginine in wounds presents a biphasic pattern: a first early burst of microbicidal NO synthesis precedes a drop in arginine concentration and an increase in ornithine and proline synthesis to promote wound healing [146, 147]. In addition, Arg1-mediated wound healing mechanisms can be employed to directly modulate parasite growth. Using an unconventional mechanism, antibodies against Heligmosomoides polygyrus larvae trigger M2/alternative activation of macrophages recruited to infection sites, and subsequently, Arg1 activity from M2 macrophages generates ornithine and polyamines that decrease larvae motility and prevent tissue damage caused by the helminth [148].

\section{Arginases and NOS2 crosstalk}

As NO is a potent inflammatory and cytotoxic mediator, its uncontrolled synthesis may lead to collateral tissue damage. Macrophages, therefore, exploit the arginase pathway to competitively regulate $\mathrm{NO}$ production and thereby counterbalance exacerbated immunity. At the molecular level, the depletion of arginine alone can regulate NO production via GCN2-driven inhibition of eIF2 $\alpha$ and a subsequent halt in NOS2 mRNA translation [95]. In addition, spermine produced by the arginase pathway can reduce mRNA levels for NOS2 and the CAT-2B transporter, as well as suppress TLRdriven cytokine synthesis by rat macrophages $[149,150]$.
As exemplified by murine models of schistosoma mansoni infection, a deficiency in Arg1 in macrophages results in uncontrolled Th2 cytokine-driven liver inflammation and fibrosis [151], as well as intestinal inflammation caused by a dysregulated Th17/Treg ratio and the synthesis proinflammatory IL-6, IL-12/IL-23p40, and NO [152]. Notably, however, Arg1 activity can also coexist with NOS2 activity. During Mycobacterium tuberculosis infection, a particular organization of macrophages in granulomas leads to the concentration of NOS2 activity in the inner regions, whereas Arg1 activity predominates in the outer regions. This helps to minimize lung pathology by surrounding zones presenting microbicidal activity with regions favoring tissue repair [153]. Such protective roles of arginase activity are nonetheless pathology-specific, as host $\operatorname{Arg} 1$ is irrelevant in some models of excessive lung inflammation and asthma [143].

Pathogens can co-opt macrophage Arg1 activity to blunt NO synthesis and escape the host immune response. For instance, M. tuberculosis coinfections with either Schistosoma mansoni or Toxoplasma gondii lead to increased Arg1 activity in lung macrophages and exacerbated disease progression [154, 155]. Pathogens can also exploit arginase activities encoded in their own genomes. This situation is exemplified by Helicobacter pylori, which can blunt NOS2 activity in macrophages, thereby promoting pathogen survival, by expressing an arginase encoded by the rocF gene [156].

\section{Granulocytes: neutrophils}

Although human granulocytes express arginase enzymes, their effector functions are surprisingly independent of arginine availability [157]. Instead, granulocytes can exert arginase-mediated immunosuppressive functions [158] reminiscent of myeloid-derived suppressor cells (MDSCs), a heterogeneous population of myeloid cells having paramount relevance for pathological disruption of arginine metabolism. Neutrophils are thus often included in the immunosuppressive MDSC population. Although neutrophils constitutively express Arg1, this enzyme is not used to metabolize arginine intracellularly $[158,159]$. Instead, they are key regulators of extracellular arginine availability as they secrete arginase-containing granules [160], a mechanism having extensive pathological implications in several conditions. For instance, compared to neutrophils from healthy individuals, neutrophils from septic shock patients display elevated $\operatorname{Arg} 2$ expression and a superior capacity to limit T cell proliferation [161]. Pharmacological arginase inhibition confirmed that this suppressive capacity is indeed partially dependent on arginase activity.

On the other hand, arginine can also enhance the phagocytosis of Staphylococcus aureus by human neutrophils [162] and sustain the synthesis of NO by mouse neutrophils 
[163]. NO synthesis in neutrophils can also exert a protective role, in this case, by preventing the production of highly damaging superoxide by these cells $[164,165]$.

\section{Myeloid-derived suppressor cells}

The MDSC population encompasses diverse types of developmentally immature cells at different stages of myelopoiesis [166]. They share the unifying property of being able to suppress $\mathrm{T}$ cell function. Although MDSCs are uniformly defined by the expression of CD11b, they exhibit considerable heterogeneity in terms of (1) their expression of argininecatabolizing enzymes, (2) their pluripotency with respect to being able to differentiate into macrophages, granulocytes, or dendritic cells depending on the cytokine and growth factor culture conditions [167], and (3) the mechanisms they employ for exerting T cell inhibition. Arg1-expressing MDSCs are prominent immunosuppressors implicated in the pathogenesis of chronic helminth infection, autoimmune diseases and graft-versus-host disease, as well as in cancer [168-173]. In neoplastic diseases, MDSCs are major contributors to the intra-tumoral arginase activity observed in both preclinical models and cancer patients [167, 174-176], in which tumor-derived factors, such as PGE2, can induce Arg1 expression via STAT3 or STAT6 [167, 177, 178]. A classic immunosuppressive mechanism ascribed to MDSCs is depletion of the extracellular arginine pool by Arg1, resulting in a reduced availability of arginine for effector $\mathrm{T}$ cells [172]. Moreover, co-expression of CAT-2B in MDSCs further supports the arginine-depleting activity of Arg1 by importing more extracellular arginine in exchange for the newly synthesized ornithine [179-181].

Arginine depletion by MDSCs exerts immunosuppressive effects via two main mechanisms. First, suboptimal concentrations of arginine lead to decreased NOS2 mRNA translation, reduced NO synthesis, and induced NOS2 uncoupling [95, 182]. When arginine is scarce, the reductase and oxygenase domains of uncoupled NOS2 can only transfer NADPH electrons to $\mathrm{O}_{2}$, thereby generating $\mathrm{O}_{2}{ }^{-}$superoxide and, via subsequent reactions, ROS and RNS [183, 184]. The production of these oxidizing species within argininestarved T cells or by neighboring MDSCs affects numerous key processes [185-187], including impaired loading of antigenic peptides onto MHC complexes in tumor cells [188], reduced responsiveness of $\mathrm{T}$ cells to cytokines or to antigenspecific stimulation [189], and even active induction of T cell hyporesponsiveness [190]. In a second, complementary manner, arginine starvation has direct, cell-intrinsic effects on $\mathrm{T}$ cells, as described in more detail below. Although MDSC activity can induce pathogenic T cell suppression, for example, by inhibiting anti-tumor T cells, it can also exert beneficial effects by limiting unwanted inflammation [191]. For instance, both IFN- $\gamma$ and IL-4 activate MDSCs at inflammation sites, thereby initiating a negative feedback loop that suppresses $\mathrm{T}$ cell activity and helps to resolve inflammation [74, 179].

\section{Dendritic cells}

Dendritic cells (DCs) are critical relays between the innate and adaptive immune systems: they integrate multiple signals, for example cytokines secreted by innate immune cells [192, 193], to ultimately instruct either reactive or tolerant adaptive immune responses. Arginases and NOS2 enzymes are prominent regulators of arginine metabolism in DCs, and in a dichotomy reminiscent to that observed for macrophages, the differential use of these pathways dynamically modulates their stimulatory outcomes. Therefore, the expression of these enzymes is tightly controlled in DCs.

In the previous studies, we identified Arg2 as a target of microRNA-155 (miR-155) in diverse activated murine DC subsets [194]. We demonstrated that in contrast to macrophages stimulated with $\mathrm{CpG}$ and IFN- $\gamma$ [195], Arg2 expression is silenced by miR-155 in activated DCs. In a series of in vitro and in vivo experiments, we demonstrated that the repression of Arg2 by miR-155 in DCs is a prerequisite for their ability to induce optimal $\mathrm{T}$ cell priming [196]. Consequently, de-repressed Arg2 activity in activated miR-155 ${ }^{-1-}$ DCs thwarts cognate $\mathrm{T}$ cell activation and proliferation.

The relevance of arginine metabolism in DCs is further highlighted by the identification of a specific DC subpopulation that is characterized by TNF- $\alpha$ and NOS 2 expression, hence known as TNF- $\alpha$, iNOS-producing DCs (Tip-DCs) [197, 198]. Tip-DCs exert pro-inflammatory roles conferring resistance to Listeria monocytogenes, Brucella melitensis, and Leishmania major infections [198-200]. Besides pathogen resistance, the pro-inflammatory activity of Tip-DCs and their interaction with tumor-specific $\mathrm{CD} 8^{+} \mathrm{T}$ cells result in superior anti-tumor responses [201]. Conversely, Tip-DCderived NO suppresses antigen-specific T cells and prevents the exacerbation of autoimmune myocarditis in vivo [202]. The activity of Tip-DCs also has detrimental consequences in Trypanosoma brucei rodent infection, a model in which IL-10 genetic administration counters pathological liver damage via the inhibition of Tip-DC maturation [203].

Dendritic cells can also acquire tolerogenic properties and exert immunosuppressive effects by modulating their metabolism of arginine. For instance, murine DCs can reinforce the suppressive activity of TGF- $\beta$-stimulated MDSCs: in response to ornithine and spermine synthesized via the arginase pathway in MDSCs, DCs upregulate Arg1 and indoleamine 2,3-dioxygenase 1 (IDO1), thereby further strengthening the immunosuppressive program triggered by TGF- $\beta$ [204]. Another prominent example is fetal conventional DCs (cDCs). Fetal cDC subpopulations are similar to 
those present in adults, with one major exception: fetal cDCs promote tolerogenic responses and generate higher frequencies of $\mathrm{FOXP}^{+}$regulatory $\mathrm{T}$ cells (Treg). A recent report demonstrated that the co-culture of adult $\mathrm{T}$ cells with fetal or adult DCs resulted in similar levels of T cell proliferation, but that the fetal DCs induced a reduction in the synthesis of the pro-inflammatory cytokines IL- 2 and TNF- $\alpha$ and an increase in the production of IL- 4 by the co-cultured T cells [205]. A key differentiating factor of the fetal DCs was a markedly greater expression of ARG2. The authors further showed that TNF- $\alpha$ expression was partially inhibited by ARG2-mediated arginine depletion, as arginine supplementation or pharmacological arginase inhibition restored TNF- $\alpha$ synthesis. These observations emphasize the importance of arginine depletion as a physiological strategy implemented by DCs to prevent detrimental $\mathrm{T}$ cell reactivity.

\section{Erythroid cells}

Erythroid cells also express arginine-metabolizing enzymes [206, 207]. Using analogous mechanism to fetal DCs, ARG2 activity in $\mathrm{CD} 71^{+}$erythroid cells contributes to the suppression of innate and adaptive immunity in immunologically delicate contexts, such as during pregnancy or postnatally. Interestingly, pregnancy induces a subset of maternal CD71 ${ }^{+}$ erythroid cells that suppress allogeneic $\mathrm{T}$ cell responses via ARG2 activity and PD-L1 expression, therefore, promoting fetomaternal tolerance [208]. However, ARG2 is expressed not only in maternal CD $71^{+}$erythroid cells, but also in neonatal $\mathrm{CD} 71^{+}$erythroid cells. Therefore, neonates actively engage arginine-depleting immunosuppressive mechanisms, in opposition to the established notion that immaturity of immune cells underlies suboptimal immunity in neonates [209]. In line with this notion, recent investigations demonstrated that $\mathrm{CD} 71^{+}$erythroid cells suppress both cellular and humoral adaptive immune responses against Bordetella pertussis - a common pathogen of the neonatal respiratory tract-as well as innate immune responses [210, 211]. More specifically, Arg2-expressing CD71 ${ }^{+}$erythroid cells regulate $\mathrm{CD} 11 \mathrm{~b}^{+}$cell phagocytosis in an arginine-dependent manner. They also illustrate how ancient metabolic functions, such as mitochondrial arginase activity, can be repurposed to modulate appropriate immune reactivity in immunologically delicate scenarios, such as to maintain fetomaternal tolerance by preventing undesirable immune reactivity directed against the fetus.

\section{T cells}

A seminal study in 1968 first demonstrated that arginine depletion in T cell lymphocytes infected by arginase-expressing mycoplasma inhibits their activation and proliferation in vitro [25]; this inhibition was arginine-dependent as arginine repletion at $10 \mathrm{~mol} / \mathrm{L}$ relieved the block in activation and proliferation. Subsequent experiments confirmed that arginine depletion depresses $\mathrm{T}$ cell proliferation in vitro in a dose-dependent manner, and that maximal proliferation occurred after replenishing arginine to the concentrations typically found in plasma (around $100 \mu \mathrm{mol} / \mathrm{L}$ ) [82, 212, 213]. Further increases in arginine concentrations beyond this threshold had no additional effect on proliferation [5, $214,215]$. Notably, proliferation and memory formation presented a more marked dependency on arginine availability for $\mathrm{CD} 8^{+} \mathrm{T}$ cells than for $\mathrm{CD} 4^{+} \mathrm{T}$ cells [216]. In addition, dietary arginine supplementation improved thymic weight and thymic lymphocyte counts in rats, increased ex vivo reactivity of human and rat $\mathrm{T}$ lymphocytes to PHA and concanavalin A [30,217], and T cell cytotoxicity [218].

\section{Effects of arginine starvation on T cell biology}

A plethora of studies has demonstrated that the culture of $\mathrm{T}$ cells under limiting arginine concentrations impairs their function via downregulation of the $\mathrm{CD} 3 \zeta$ subunit of the $\mathrm{T}$ cell receptor (TCR) complex (Fig. 3). This subunit is indispensable for the assembly of the TCR complex [219-221] and couples TCR ligation with the downstream signal transduction cascade mediating $T$ cell activation via phospho-

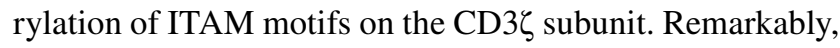
ex vivo arginine availability within physiological ranges modulates the expression level of $\mathrm{CD} 3 \zeta[222,223]$ via a mechanism that is not yet fully elucidated [224]. Interestingly, supplementation of culture media with citrulline, a precursor of arginine synthesis, can increase CD3 $\zeta$ expression under low arginine conditions by extending the half-life of its mRNA [223]. Downregulation of CD3 $\zeta$ expression blocks $\mathrm{T}$ cell proliferation without impairing $\mathrm{T}$ cell viability [158] (Fig. 3). Collectively, these findings indicate that regulation of $\mathrm{CD} 3 \zeta$ expression is a prominent mechanism for modulating $\mathrm{T}$ cell activation. Several examples underline the physiological relevance of these findings. For example, as mentioned above, $H$. pylori co-opts this regulatory mechanism to inhibit $\mathrm{CD} 3 \zeta$ expression and thereby restrict T cell activity by depleting arginine via the arginase enzyme encoded by its rocF gene [225]. Other studies have demonstrated that dying polymorphonuclear leukocytes release Arg1 and thereby induce the depletion of extracellular arginine, leading to the loss of $\mathrm{CD} 3 \zeta$ expression by $\mathrm{T}$ cells in inflamed microenvironments $[158,179]$.

In addition to $\mathrm{CD} 3 \zeta$ downregulation, arginine deprivation modulates TCR signaling by impairing cofilin dephosphorylation in activated human T cells [226] (Fig. 3). Dephosphorylated cofilin increases the dynamics of F-actin networks [227], which is critical for T cell activation, because it regulates TCR sensitivity thresholds in immune synapses 


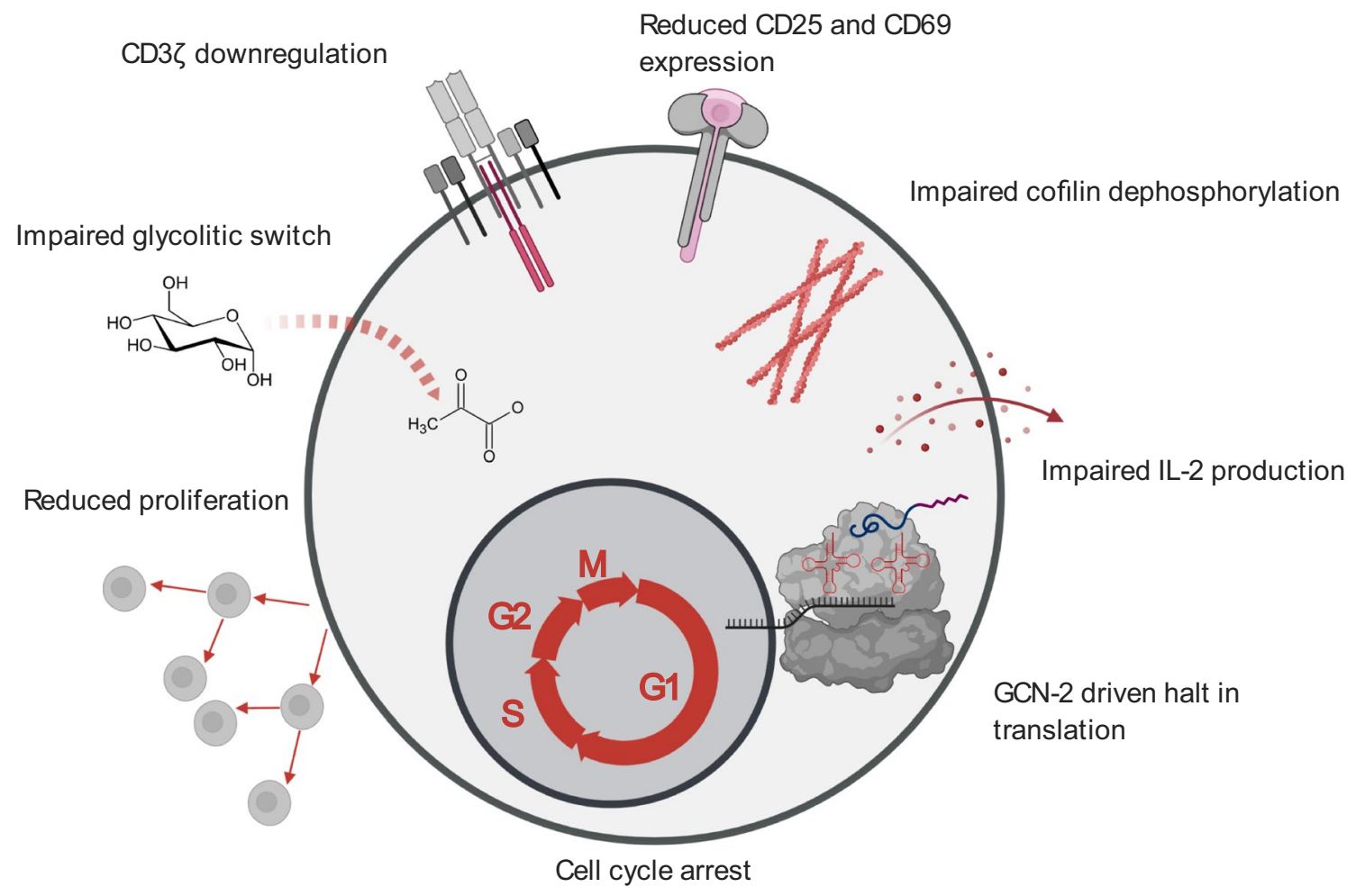

Fig. 3 Overview of the deleterious effects that arginine starvation exerts on T cell functions

[228]. Impaired cofilin dephosphorylation correlates with a decrease in the F-actin content and decreased accumulation of CD2 and CD3 in the immune synapse of activated T cells, ultimately decreasing $\mathrm{T}$ cell proliferation and cytokine synthesis [226]. In vitro activation with phorbol myristate acetate (PMA), which bypasses the requirement for TCR signaling, does not suffice to rescue poor $\mathrm{T}$ cell proliferation in arginine-depleted conditions [229]. This observation implies that the inhibitory effect of arginine depletion on $T$ cell proliferation is not caused exclusively by decreased CD3 $\zeta$ expression and TCR signaling. Other mechanisms must also be at play. In agreement with this, arginine depletion has been implicated in other molecular alterations, such as impaired nuclear translocation of $\mathrm{NF} \kappa \mathrm{B}-\mathrm{p} 65$ [229].

Arginine deficiency leads to decreased IL-2 production by cultured human $\mathrm{T}$ cells, and reduced expression of the early activation markers CD25 and CD69 [216] (Fig. 3). Seminal publications first proposed that arginine deprivation decreases IL-2 concentrations in T cell culture supernatants by regulating translation of its mRNA and by modifying its autologous consumption. However, minimal arginine concentrations of $10-100 \mu \mathrm{M}$ suffice for enabling robust $\mathrm{T}$ cell proliferation and IL-2 production [216].

Arginine starvation also regulates D-type cyclins (D1, D2, and D3) and cyclin-dependent kinases (CDK4 and CDK6) in $\mathrm{T}$ cells, therefore, regulating progression through the cell cycle [230] (Fig. 3). For instance, in activated T cells, the absence of arginine blocks cyclin D3 and CDK4 upregulation, but increases CDK6 expression and results in the arrest of $T$ cells in the $G_{0}-G_{1}$ phase of the cell cycle [231, 232], suggesting that sufficient arginine is a requirement for cell cycle entry.

Amino acid depletion halts protein synthesis due to the accumulation of uncharged aminoacyl-tRNAs, leading to activation of the kinase GCN2, which senses the binding of uncharged tRNAs to ribosomes and halts mRNA translation. More precisely, activated GCN2 phosphorylates the translation initiation factor eIF $2 \alpha$ and inhibits protein synthesis by blocking the binding of the eIF 2 complex to methionine aminoacyl-tRNA [233]. GCN2 activation leads to an arrest in T cell proliferation, induces $\mathrm{T}$ cell anergy, impairs cytotoxic effector functions, and further downregulates the expression of $\mathrm{CD} 3 \zeta$ in mouse $\mathrm{CD} 8^{+} \mathrm{T}$ cells $[234,235]$. In line with these observations, the absence of arginine promotes the phosphorylation of eIF $2 \alpha$ and is associated with decreased translation rates [236] (Fig. 3).

A recent report demonstrated that arginine starvation can also impact the glycolytic switch in activated $\mathrm{T}$ cells: arginine starvation caused by adding recombinant Arg1 to cultured $\mathrm{T}$ cells blocked their glycolytic function, without affecting mitochondrial biogenesis or mitochondrial functionality [237] (Fig. 3). Conversely, the addition of 
supraphysiological concentrations of arginine to T cell cultures resulted in perturbations of energy metabolism and promoted $\mathrm{CD} 8^{+} \mathrm{T}$ cell anti-tumor activity in vivo upon reinfusion into tumor-bearing mice [5]. Remarkably, T cells also employ mechanisms to sustain intracellular arginine pools and counteract arginine deprivation: when confronted with arginine scarcity caused by, for instance, Arg 1-expressing myeloid cells [172], Jurkat T cells upregulate the transcription of the ASS1 gene to promote arginine biosynthesis [218]. In line with this, reengineering CAR-T cells to express arginine-synthetizing ASS1 and OTC enhances CAR-T cell in vivo persistence and activity against solid and hematologic tumors [238].

\section{Arginase 2 regulates the intracellular metabolism of arginine in T cells}

Most investigations on the influence of arginine metabolism on T cells have focused on mechanisms affecting extracellular arginine concentration, such as Arg1-mediated arginine depletion in the tumor microenvironment. Nonetheless, $\mathrm{T}$ cell activation encompasses an intense arginine uptake $[4,5]$, and in human endothelial cells, distinct intracellular arginine pools are not freely interchangeable [64]. Hence, the extracellular arginine supply may not serve as a reliable proxy for intracellular arginine availability. Mounting evidence suggests that the intracellular metabolism of arginine profoundly alters $\mathrm{T}$ cell function. Arg2 has recently emerged as a cell-autonomous regulator of mouse and human activated $\mathrm{T}$ cells. Notably, pharmacological inhibition of arginases increases in vitro activation and survival of human $\mathrm{T}$ cells, which express ARG2 but not ARG1 [3]. Along similar lines, activated $\mathrm{Arg} 2^{-/-}$mouse $\mathrm{T}$ cells present enhanced in vitro survival and increased intracellular arginine levels - the latter being indicative of reduced arginase activity in these cells [3]. Importantly, such experiments were performed under excess arginine conditions, hence independent of extracellular arginine availability, and, therefore, argue for a cell-intrinsic role of the mitochondrial Arg2 (Fig. 4) in the reshaping of $\mathrm{T}$ cell arginine metabolism.

In a subsequent study, we demonstrated that germ-line Arg2 deletion and adoptive transfer of $\operatorname{Arg} 2^{-/-} \mathrm{CD} 8^{+} \mathrm{T}$ cells significantly reduce tumor growth in preclinical cancer models by enhancing $\mathrm{CD} 8^{+} \mathrm{T}$ cell activation, and endowing these cells with more robust cytotoxic function, memory $\mathrm{T}$ cell formation, and persistence [215]. Furthermore, Arg2-deficiency in $\mathrm{CD}^{+} \mathrm{T}$ cells strongly synergized with PD-1 blockade for the control of tumor growth and animal survival. Although $\mathrm{Arg} 2^{-/-} \mathrm{CD}^{+} \mathrm{T}$ cells exhibited accelerated and more robust activation kinetics, their proliferative capacity remained unaffected. All these alterations occurred in an otherwise Arg2-proficient background in vivo and were independent of the extracellular arginine concentration in vitro. This suggests that the observed alterations were caused primarily by cell-autonomous mechanisms and

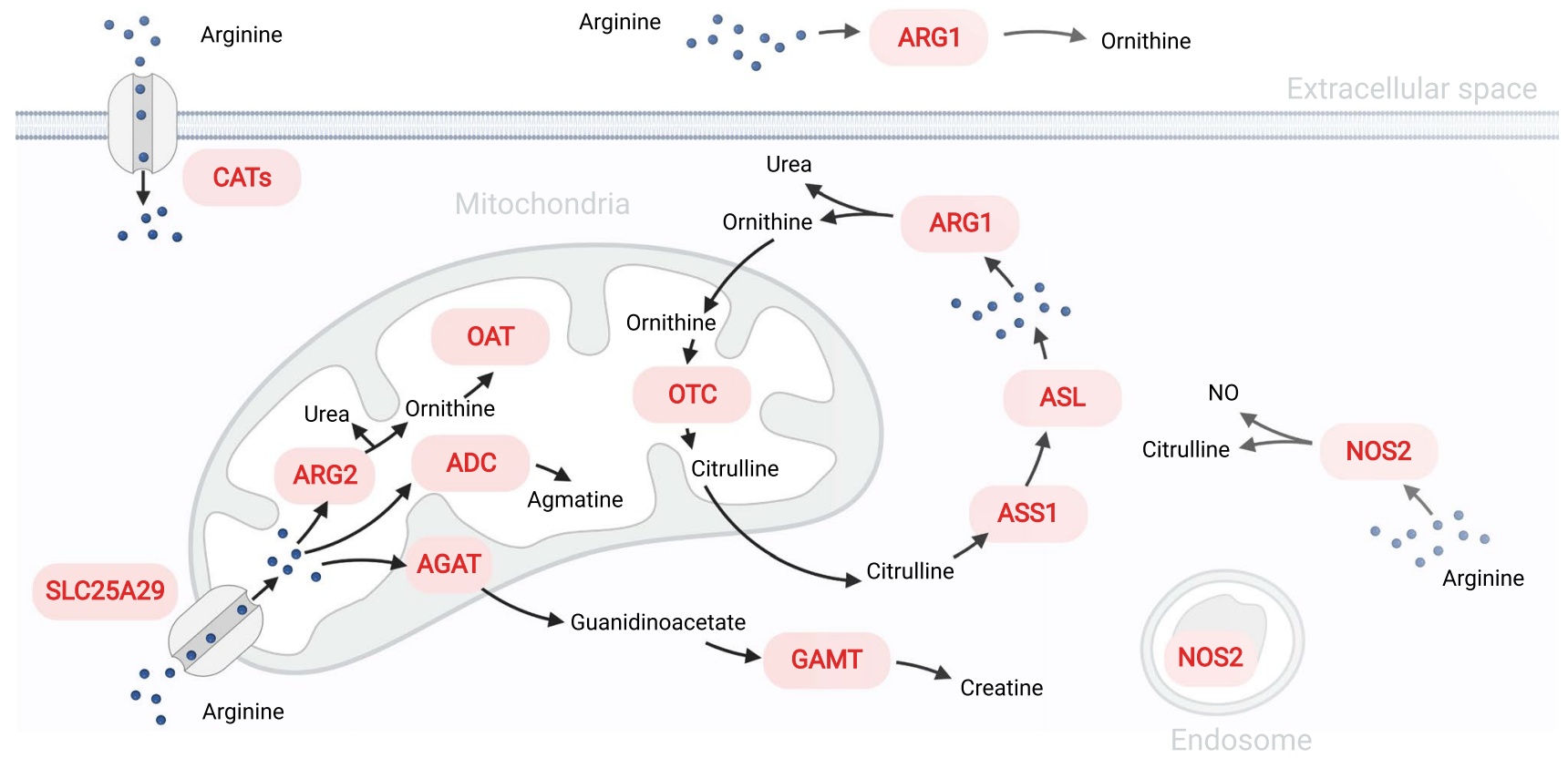

Fig. 4 Subcellular localization of proteins involved in arginine metabolism. Abbreviations: $A D C$ arginine decarboxylase, $A G A T$ arginine:glycine amidinotransferase, $A R G$ arginase, NOS2 nitric oxide synthase 2, ASS1 argininosuccinate synthase 1, ASL argininosuccinate lyase, CATs cationic amino acid transporters, GAMT guanidinoacetate $N$-methyltransferase, OTC ornithine carbamoyltransferase, OAT ornithine aminotransferase 
emphasizes the critical importance of intracellular arginine pools relative to the extracellular arginine supply (Fig. 4).

Strikingly, we also observed that the depletion of $\mathrm{CD} 4^{+}$ $\mathrm{T}$ cells selectively improves tumor control in Arg2-deficient mice. These results suggest a supportive role of Arg2 for the regulatory activity exerted by certain $\mathrm{CD} 4^{+} \mathrm{T}$ cell subsets in tumor-bearing mice. Interestingly, a very recent report demonstrated that $\mathrm{T}_{\text {regs }}$ found in healthy human skin and in metastatic melanoma [239] express Arg2. Conversely, the expression of $\operatorname{Arg} 2$ in $\mathrm{T}_{\text {regs }}$ infiltrating psoriatic skin is significantly less. Interestingly, the expression of Arg2 in $T_{\text {regs }}$ attenuated mTOR activity and endowed them with enhanced suppressive activity in vitro and increased tissue persistence of adoptively-transferred $\mathrm{T}_{\text {regs }}$ [239]. Taken together, these observations suggest that the intracellular arginine concentration and its regulation by $\operatorname{Arg} 2$ dictate $\mathrm{T}_{\text {reg }}$ expansion and survival in different microenvironments, and unveil Arg2 as a putative therapeutic target in both autoimmune and neoplastic diseases.

\section{Nitric oxide synthesis is a key modulator of T cell biology}

Several studies have demonstrated that the NOS pathway can affect $\mathrm{T}$ cell biology. High NO concentrations can exert pro-apoptotic effects via different mechanisms, such as p53 accumulation and CD95 signaling [91, 240]. T cell activation also results in $\mathrm{NO}$ accumulation [241], in a mechanism regarded as a self-limiting circuit that triggers $\mathrm{T}$ cell apoptosis via inhibition of the anti-apoptotic Bcl-2 [242]. In line with these observations, endogenous NOS2 in mouse T cells regulates their contraction phase, endowing Nos $2^{-/-} \mathrm{T}$ cells with enhanced resistance to death by neglect and death after withdrawal of trophic stimuli [243]. Thus, mice lacking the Nos2 gene showed an increased frequency of $\mathrm{CD}^{+}$and $\mathrm{CD}^{+}$memory $\mathrm{T}$ cells after immunisation [243]. NO also dampens $T$ cell proliferation and differentiation by impairing IL-2 synthesis [244, 245] and IL-2R signaling pathways [246]. NO can inhibit the binding of JAK3 to the common gamma-chain, thus dampening responses induced by the cytokine receptors for IL-2, IL-4, IL-7, IL-9, and IL-15 [247]. NO can also inhibit signaling via STAT5, a key factor for the maintenance of effector $\mathrm{CD} 8^{+} \mathrm{T}$ cell responses, as well as the ERK and AKT pathways [169]. In addition, RNOS derived from NO can affect conformational flexibility of binding of the TCR/CD8 complex to the pMHC-I (peptide-MHC-I) complex, thus limiting CD8 T cell anti-tumor activity [188, 248].

\section{Creatine uptake supports anti-tumor T cell functions}

Creatine and phosphocreatine buffer intracellular highenergy phosphate, acting as storage systems of the energy required for ATP synthesis [249]. The uptake of creatine has recently been reported to support anti-tumor $\mathrm{T}$ cell functions in murine melanoma and colorectal carcinoma models [250]. Tumor-infiltrating T cells express low levels of creatine-synthesizing enzymes AGAT and GAMT and primarily rely on creatine uptake via increased expression of its plasma membrane transporter SLC6A8 [250]. Interestingly, intraperitoneal creatine supplementation synergized with PD-1 blockade therapies for the control of tumor growth. These observations are reminiscent of similar synergistic results observed after PD-1 axis blockade in combination with dietary arginine supplementation [251] or Arg2 genetic deletion [215]. Therefore, whether arginine availability and its intracellular metabolism impact on creatinine levels in human T cells (see Fig. 2) is a question that merits further exploration.

\section{B cells}

Only a few studies have addressed how arginine availability and arginine metabolism influence B lymphocyte biology. In comparison to $\mathrm{T}$ cells, B lymphocytes are less sensitive to arginine depletion. Decreased plasma arginine concentrations-via Arg1 overexpression in the small intestine- - did not alter peripheral B cell proliferation or cytokine secretion. However, the same study demonstrated that arginine depletion led to an impaired developmental transition from pro-B to pre-B cells in the bone marrow, resulting in reduced B cell cellularity in secondary lymphoid organs [252]. In addition, mice fed with arginine-free diets showed impaired mucosal immunity against tetanus toxoid, as no toxin-specific fecal $\operatorname{IgA}$ were detected in these mice [253]. Single-cell RNA-seq experiments demonstrated that $\mathrm{B}$ cells in human lung tumors express ARG1 [254]. However, the roles of arginases in B cells remain mostly unaddressed. Conversely, it has been demonstrated that NOS2 is an intrinsic factor for plasma cell survival in vitro and in vivo, as its activity is critical for the response of plasma cells to pro-survival signals, provided by APRIL and IL-6 derived from bone-marrow stromal cells [255].

\section{Natural killer cells}

The modulatory role of arginine extends to human natural killer (NK) cells. Early studies showed that arginine supplementation enhanced the cytotoxic activity of $\mathrm{CD} 56^{+}$ human NK cells in vitro, as well as in vivo after 3 days of arginine supplementation in both healthy volunteers [256] and breast cancer patients [257]. Arginine supplementation in mice resulted in a similar observation, namely, enhanced poly IC-inducible NK cell activity [258]. Conversely, arginine starvation of cultured NK-92 cells and ex vivo human NK cells limited their proliferation, reduced expression of the NKp46 and NKp30 activating receptors, and of the NK 
$\zeta$ chain, and reduced their cytotoxicity and IFN- $\gamma$ secretion [259]. Similarly, other studies showed that arginine depletion by arginase activity derived from human granulocytes severely impairs the proliferation and IFN- $\gamma$ secretion by primary and in vitro IL-2-activated human NK cells [260]. Interestingly, these effects occurred by a GCN-2 independent mechanism. Furthermore, ARG1 activity derived from hepatitis $\mathrm{C}$ virus-induced MDSCs has also been shown to suppress IFN- $\gamma$ production by NK cells [261].

Several reports have shown that the NOS pathway is active in NK cells. Unlike other immune cells, NK cells constitutively express the endothelial NOS or NOS3 [262]. The synthesis of NO by NK cells supports their cytotoxic functions in different in vitro settings. NK-derived NO synthesis has been proposed to act as an accessory cytotoxic mechanism that contributes to DNA fragmentation and cell lysis of NK targets [263]. In line with this hypothesis, a progressive increase in NO synthesis by IL-2 activated NK cells correlated positively with their capacity to lyse NKresistant target cells [264]. Furthermore, the NOS inhibitors L-NMMA and L-NAME were able to partially inhibit the cytotoxic efficacy of NK cells [263, 264]. As mentioned above for granulocytes, NOS inhibitors can also decrease arginine-dependent NK cytotoxicity by interfering with arginine uptake.

\section{Arginine metabolism in cancer}

Multiple reports have documented increased arginase activity in both animal models of cancer [167] and patients with colon, lung, breast, thyroid, or prostate cancer [174, 175]. Elevated arginine catabolism is a common hallmark of the TME. A pioneering study showed increased expression of arginases and NOS enzymes in neoplastic prostate epithelium compared to the surrounding healthy tissue, and that $\mathrm{CD}^{+} \mathrm{T}$ cells infiltrating these malignant tissues displayed a terminally differentiated phenotype, becoming irresponsive to immune stimuli [175]. In addition, treatment with arginase and NOS inhibitors restored $\mathrm{CD} 8^{+} \mathrm{T}$ cell responsiveness. Subsequent studies showed that Arg2 expression in mouse renal cell carcinoma suffices to induce arginine depletion and immunosuppress co-cultured human T cells [265]. These observations suggested, for the first time, that arginine depletion by arginases constitutes a major mechanism by which cancer cells induce in situ immunosuppression.

Enforcing arginine depletion in the tumor microenvironment might, however, seems counterproductive for tumor growth: amino acids are essential for tumor cell proliferation as well as for stromal and vascular tissue remodeling required for tumor spread. Several lines of evidence support the notion that immunosuppression by arginine depletion is more beneficial for tumor growth than the constraint resulting from reduced access to arginine [266]. In addition, enforcing arginase activity in cancer cells might promote tumor progression by providing neoplastic cells with polyamines and other arginine subproducts that stimulate cell proliferation, and the tumor cells could adapt to limited arginine by upregulating amino acid transporters or by lowering their sensitivity to GCN2 and mTOR signaling. As described above, $\mathrm{T}$ cells have specific requirements for specific amino acids and arginine depletion activates GCN2 to block entry into $\mathrm{S}$ phase following $\mathrm{T}$ cell stimulation [232], suggesting that sufficient access to arginine is a prerequisite for cell cycle entry in $\mathrm{T}$ cells.

These mechanisms are also reminiscent of healing responses-used to control and prevent immune-mediated damage in inflamed and wounded tissues. A central hypothesis in current investigations is that malignant lesions hijack tissue healing pathways and subvert these mechanisms for suppressing anti-tumor immunity and creating potent protumoral immune checkpoints. Macrophages and cells from the myeloid compartment are a paradigm of such hypotheses. M1 macrophages are regarded as mediators of resistance against tumor growth: they produce inflammatory cytokines, such as IL- $1 \beta$ and TNF- $\alpha$, which promote Th1 responses. M1 macrophages are also responsible for NO production [267], causing cell cycle arrest and tumor cell cytostasis or apoptosis, and further sensitizing cancer cells to TNFinduced cytotoxicity. On the contrary, macrophages conditioned by anti-inflammatory cytokines released in tumor microenvironment - such as IL-4, IL-10, amongst otherspolarize towards the M2 phenotype [268]. M2-polarised macrophages induce $\mathrm{Th} 2$ responses and are characterized by the production of anti-inflammatory mediators, such as Arg1. Both in patients and mice, tumor-associated macrophages (TAMs) promote tumor progression and protumoral tissue remodelling $[267,269]$. Activated similar to M2 macrophages [105, 106], TAMs express substantial amounts of ARG1, leading to an over-production of ornithine, which can be used by ODC to synthesize polyamines, such as putrescine, spermidine, and spermine, and thus promote cancer cell proliferation and tumor vascularization [270, 271].

In parallel, murine and human neoplastic cells can secrete soluble factors - such as GM-CSF and G-CSF-that alter myelopoiesis and lead to the recruitment and accumulation of MDSCs [272]. For instance, increased numbers of circulating MDSCs exhibiting high Arg1 expression have been documented in glioblastoma patients [273]. In tumors, MDSCs frequently express Arg1 and reflect functional similarities to alternatively activated M2 macrophages [1, 274], including IL-10, TGF- $\beta$, and IDO expression [275]. Interestingly, it has been demonstrated that $\mathrm{CD} 3 \zeta$ chain downregulation caused by tumor-derived MDSCs overexpressing Arg 1 
might be more detrimental for $\mathrm{CD} 4^{+} \mathrm{T}$ cells than $\mathrm{CD} 8^{+} \mathrm{T}$ cells [276].

Counterintuitively, arginine-depleting immune cells might contribute to the establishment of barriers to natural and therapy-induced anti-tumor immunity, even if tumor cells do not catabolize arginine themselves. In light of these findings, arginine supplementation could seem counterproductive, feed-forwarding the establishment of an immune barrier. However, the combination of arginine supplementation with therapies that release other immunosuppressive barriers, such as PD-L1 blockade, has proven successful in preclinical models of osteosarcoma in mice [251]. Therefore, restoring arginine in the TME boosts anti-tumor T cells in a context, where the PD-1/PD-L1 axis is also disarmed for the in situ repression of $\mathrm{T}$ cells. Thus, and as discussed below, the exploitation of non-redundant immunosuppressive mechanisms bears great promise for the immediate future of cancer immunotherapies.

\section{Arginases as therapeutic solutions and targets in cancer}

Numerous clinical trials have explored arginine depletion to combat different malignancies, such as lymphoblastic and acute myeloid leukemias, melanoma, as well as pancreatic and liver carcinomas [277]. These therapeutic strategies exploit a frequent ASS1 deficiency in tumor cells, which renders malignant cells auxotrophic for arginine [278]. Therefore, arginine deprivation in the bloodstream has been tested using the administration of two different pegylated proteins, the mycoplasma-derived arginine deiminase (ADIPeg) or human Arginase 1 (Arg1-Peg).

Although ADI-Peg has demonstrated efficacious antitumor activity in ASS1-deficient tumors, such as HCC, ADIPeg is significantly immunogenic and induces the production of blocking antibodies. Furthermore, ADI-Peg also leads to the synthesis of ammonia, a toxic product, causing neutropenia and neurological impairment [279]. Alternatively, PegArg 1 can also reduce arginine serum levels in vivo without inducing noticeable toxicity [280] and without evidence of immunogenicity. Consequently, Peg-Arg1 represents a safer and more efficacious therapy that has exhibited significant anti-tumor benefits in multiple preclinical cancer models and in cancer patients [277].

Arginase inhibitors have also been tested for cancer treatment. The most notorious case is that of the CB-1158 arginase inhibitor. In mouse preclinical models, CB-1158 released MDSC-mediated $\mathrm{T}$ cell immunosuppression and reduced tumor growth in a $\mathrm{CD} 8^{+} \mathrm{T}$ cell and NK cell-dependent manner [281]. Moreover, in preclinical models, CB-1158 also boosted the effect of standard-of-care immunotherapiessuch PD-L1 checkpoint blockade, and adoptive T or NK cell therapies - and improved efficacy of the chemotherapeutic agent gemcitabine.

\section{Concluding remarks and perspectives}

Early work in the arginine metabolism field focused on examining defects in arginine-starved immune cells. Subsequent studies identified key metabolic pathways driving arginine metabolism in immune cells and defined major roles of distinct immune cell lineages in immune responses to arginine depletion. Over the past decade, an increasingly refined picture has emerged of how cellular arginine metabolism affects the differentiation, expansion, and maturation of both macrophage, DC and T cell subsets. In parallel to a need for a better understanding of arginine metabolism in other immune cell lineages, some aspects of arginine relevance for immune cell biology remain unaddressed. Although intracellular arginine compartmentalization has been described, the mechanisms of arginine trafficking from the cytosol to key organelles, such as the mitochondrion, remain unknown. In addition, it is still unclear what mechanisms mediate arginine sensing in such organelles, a question of paramount importance considering the relevance of intracellular arginine metabolism for dictating immune outcomes.

It has also become evident that distinct arginine usages result in lineage- and subset-specific pro- or anti-inflammatory phenotypes. Translating and further expanding our knowledge on the metabolic fate of arginine is likely to lead to the development of new therapeutic strategies in many disease areas. Understanding how arginine metabolism integrates with other regulatory mechanisms, such as microRNA-155 upregulation in activated CD8 T cells, might reveal critical metabolic nodes that might be readily available for genetic or pharmacologic intervention. Given our growing appreciation of how arginine metabolism dictates divergent immune phenotypes, e.g., Arg2 limits T cell activation and effector functions but promotes $\mathrm{T}_{\text {reg }}$ metabolic fitness, integrating arginine metabolism and the inflammatory milieu in which $\mathrm{T}$ cells operate will be crucial for the development of next-generation immunotherapies. Isoformspecific arginase inhibitors or genetic engineering of arginine metabolic pathways could prove to be valuable therapeutic tools to favor immunogenic or tolerogenic responses in personalized immunotherapies.

Acknowledgements We are grateful to all members of the lab for inspiring discussions and experimental help. All figures were created using BioRender.com.

Authors' contributions AAML and WR wrote and critically revised the manuscript. 
Funding Open Access funding provided by Université de Genève. This work was supported by grants from the Swiss National Science Foundation, The Geneva Cancer League, the Swiss Cancer League and an "Innogap" grant from the University of Geneva.

\section{Declarations}

Conflict of interest The authors have no conflict of interest.

Open Access This article is licensed under a Creative Commons Attribution 4.0 International License, which permits use, sharing, adaptation, distribution and reproduction in any medium or format, as long as you give appropriate credit to the original author(s) and the source, provide a link to the Creative Commons licence, and indicate if changes were made. The images or other third party material in this article are included in the article's Creative Commons licence, unless indicated otherwise in a credit line to the material. If material is not included in the article's Creative Commons licence and your intended use is not permitted by statutory regulation or exceeds the permitted use, you will need to obtain permission directly from the copyright holder. To view a copy of this licence, visit http://creativecommons.org/licenses/by/4.0/.

\section{References}

1. Bronte V, Zanovello P (2005) Regulation of immune responses by L-arginine metabolism. Nat Rev Immunol 5:641-654

2. Nieves C, Langkamp-Henken B (2002) Arginine and immunity: a unique perspective. Biomed Pharmacother 56:471-482

3. Peranzoni E et al (2008) Role of arginine metabolism in immunity and immunopathology. Immunobiol 212:795-812

4. Murray PJ (2016) Amino acid auxotrophy as a system of immunological control nodes. Nat Immunol 17:132-139

5. Geiger $\mathrm{R}$ et al (2016) L-arginine modulates $\mathrm{T}$ cell metabolism and enhances survival and anti-tumor activity. Cell 167:829-842.e13

6. Vincendeau $\mathrm{P}$ et al (2003) Arginases in parasitic diseases. Trends Parasitol 19:9-12

7. Yu YM et al (2001) Arginine and ornithine kinetics in severely burned patients: increased rate of arginine disposal. Am J Physiol-Endocrino Metab 280:509-517

8. Wilmore D (2004) Enteral and parenteral arginine supplementation to improve medical outcomes in hospitalized patients. J Nutr 134:2863S-2867S (American Institute of Nutrition)

9. Redmond HP et al (1998) Immunonutrition: the role of arginine 14:599-604

10. Scull CW, Rose WC (1930) Arginine metabolism I: the relation of the arginine content of the diet to the increments in tissue arginine during growth. J Biol Chem 89:109-123

11. Castillo L et al (1994) Plasma arginine kinetics in adult man: response to an arginine-free diet. Metabolism. https://doi.org/ 10.1016/0026-0495(94)90166-X

12. Castillo L et al (1993) Plasma arginine and citrulline kinetics in adults given adequate and arginine-free diets. Proc Natl Acad Sci USA. https://doi.org/10.1073/pnas.90.16.7749

13. Nakagawa I, Takahashi T, Suzuki T, Kobayashi K (1963) Amino acid requirements of children: minimal needs of tryptophan, arginine and histidine based on nitrogen balance method. J Nutr 80:305-310

14. Schulze E, Steiger E (1886) Ueber einen neuen stickstoffhaltigen Bestandtheil der Keimlinge von Lupinus luteus. Berichte der Dtsch Chem Gesellschaft. https://doi.org/10.1002/cber.18860 1901266
15. Hedin SG (1895) Eine Methode, das Lysin zu isoliren, nebst einigen Bemerkungen Über das Lysatinin. Z Physiol Chem 21:155-168

16. Krebs HA, Henseleit K (1932) Untersuchungen über die Harnstoffbildung im Tierkörper. Klin Wochenschr 11:757-759

17. Withers PC (1998) Urea: diverse functions of a 'waste' product. Clinical Experimental Pharmacol Physiol. https://doi.org/10. 1111/j.1440-1681.1998.tb02284.x

18. Meijer AJ, Lamers WH, Chamuleau RAFM (1990) Nitrogen metabolism and ornithine cycle function. Physiol Rev. https:// doi.org/10.1152/physrev.1990.70.3.701

19. Newsholme P, Brennan L, Rubi B, Maechler P (2005) New insights into amino acid metabolism, $\beta$-cell function and diabetes. Clin Sci. https://doi.org/10.1042/CS20040290

20. Barbul A (1986) Arginine: biochemistry, physiology, and therapeutic implications. J Parenter Enter Nutr. https://doi.org/10. 1177/0148607186010002227

21. Redmond HP, Daly JM (1993) Arginine. Nutr Immunol. https:// doi.org/10.1007/978-1-4615-2900-2_7

22. Fitch CA, Platzer G, Okon M, Garcia-Moreno BE, McIntosh LP (2015) Arginine: its $\mathrm{pKa}$ value revisited. Protein Sci 24:752-761

23. Wallis M (1974) On the frequency of arginine in proteins and its implications for molecular evolution. Biochem Biophys Res Commun 56:711-716

24. King JL, Jukes TH (1969) Non-darwinian evolution. Sci 164:788-798

25. Barile MF, Leventhal BG (1968) Possible mechanism for mycoplasma inhibtion of lymphocyte transformation induced by phytohaemagglutinin. Nature 220:751-752

26. Osunkoya BO, Adler WH, Smith RT (1970) Effect of arginine deficiency on synthesis of DNA and immunoglobulin receptor of burkitt lymphoma cells. Nature 227:398-399

27. Barbul A, Rettura G, Levenson SM, Seifter E (1977) Arginine: a thymotropic and wound-healing promoting agent. Surg Forum 28:101-103

28. Tong BC, Barbul A (2004) Cellular and physiological effects of arginine. Mini Rev Med Chem 4(8):823-832. https://doi.org/10. 2174/1389557043403305

29. Mandal A (2006) Do malnutrition and nutritional supplementation have an effect on the wound healing process? J Wound Care 15:254-257

30. Barbul A, Lazarou S, Efron D, Wasserkrug HL, Efron G (1990) Arginine enhances wound healing and lymphocyte immune response in humans. Surgery 108:331-336

31. Bansal V et al (2005) Interactions between fatty acids and arginine metabolism: implications for the design of immune-enhancing diets. J Parenter Enter Nutr 29:S75-S80

32. Grimble RF (2005) Immunonutrition. Curr Opin Gastroenterol 21:216-222

33. Ochoa JB, Makarenkova V, Bansal V (2004) A rational use of immune enhancing diets: when should we use dietary arginine supplementation? Nutr Clinical Pract 19:216-225

34. Daly JM et al (1988) Immune and metabolic effects of arginine in the surgical patient. Ann Surg. https://doi.org/10.1097/00000 658-198810000-00013

35. Braga $M$ et al (1996) Immune and nutritional effects of early enteral nutrition after major abdominal operations. Eur J Surg 162:105-112

36. Bower RH et al (1995) Early enteral administration of a formula (impact $\rho$ ) supplemented with arginine, nucleotides, and fish oil in intensive care unit patients: results of a multicenter, prospective, randomized, clinical trial. Crit Care Med. https://doi.org/10. 1097/00003246-199503000-00006

37. Morris CR et al (2005) Dysregulated arginine metabolism, hemolysis-associated pulmonary hypertension, and mortality in sickle cell disease. JAMA 294:81 
38. Powell-Tuck J (2007) Nutritional interventions in critical illness. Proc Nutr Soc 66:16-24

39. De Waele E, Malbrain MLNG, Spapen H (2020) Nutrition in sepsis: a bench-to-bedside review. Nutrients 12:1-16

40. Bode-Böger SM, Böger RH, Galland A, Tsikas D, Frölich JC (1998) L-arginine-induced vasodilation in healthy humans: pharmacokinetic-pharmacodynamic relationship. Br J Clin Pharmacol. https://doi.org/10.1046/j.1365-2125.1998.00803.x

41. Möller P, Alvestrand A, Bergström J, Fürst P, Hellström K (1983) Electrolytes and free amino acids in leg skeletal muscle of young and elderly women. Gerontology. https://doi.org/10.1159/00021 3088

42. Moller P, Bergstrom J, Eriksson S, Fürst P, Hellström K (1979) Effect of aging on free amino acids and electrolytes in leg skeletal muscle. Clin Sci. https://doi.org/10.1042/cs0560427

43. Wu G, Morris SM (1998) Arginine metabolism: nitric oxide and beyond. Biochem J 336:1-17

44. Visek WJ (1986) Arginine needs, physiological state and usual diets. Reevaluation J Nutr. https://doi.org/10.1093/jn/116.1.36

45. Mirmiran P, Moghadam SK, Bahadoran Z, Ghasemi A, Azizi F (2017) Dietary L-arginine intakes and the risk of metabolic syndrome: a 6-year follow-up in tehran lipid and glucose study. Prev Nutr Food Sci. https://doi.org/10.3746/pnf.2017.22.4.263

46. White MF (1985) The transport of cationic amino acids across the plasma membrane of mammalian cells. BBA-Rev Biomembr 822:355-374

47. Mann GE, Yudilevich DL, Sobrevia L (2003) Regulation of amino acid and glucose transporters in endothelial and smooth muscle cells. Physiol Rev 83:183-252

48. Castillo L et al (1993) Dietary arginine uptake by the splanchnic region in adult humans. Am J Physiol Endocrinol Metab 265:E532-539

49. Barbul A, Uliyargoli A (2007) Use of exogenous arginine in multiple organ dysfunction syndrome and sepsis. Crit Care Med. https://doi.org/10.1097/01.CCM.0000279188.97421.FE

50. Cheung CW, Cohen NS, Raijman L (1989) Channeling of urea cycle intermediates in situ in permeabilized hepatocytes. J Biol Chem 264:4038-4044

51. Watford M (1991) The urea cycle: a two-compartment system. Essays Biochem 26:49-58

52. Castillo L, Beaumier L, Ajami AM, Young VR (1996) Whole body nitric oxide synthesis in healthy men determined from $\left[{ }^{15} \mathrm{~N}\right]$ arginine-to- $\left[{ }^{15} \mathrm{~N}\right]$ citrulline labeling. Proc Natl Acad Sci USA. https://doi.org/10.1073/pnas.93.21.11460

53. Rose WC, Haines WJ, Warner DT (1954) The amino acid requirements of man. V. The role of lysine, arginine, and tryptophan. J Biol Chem 206:421-430

54. Featherston WR, Rogers QR, Freedland RA (1973) Relative importance of kidney and liver in synthesis of arginine by the rat. Am J Physiol. https://doi.org/10.1152/ajplegacy.1973.224.1. 127

55. Dhanakoti SN, Brosnan JT, Herzberg GR, Brosnan ME (1990) Renal arginine synthesis: studies in vitro and in vivo. Am J Physiol-Endocrinol Metab. https://doi.org/10.1152/ajpendo. 1990.259.3.e437

56. Dhanakoti SN, Brosnan ME, Herzberg GR, Brosnan JT (1992) Cellular and subcellular localization of enzymes of arginine metabolism in rat kidney. Biochem J. https://doi.org/10.1042/ bj2820369

57. Windmueller HG, Spaeth AE (1981) Source and fate of circulating citrulline. Am J Physiol-Endocrinol Metab. https://doi.org/ 10.1152/ajpendo.1981.241.6.e473

58. Rabier D, Kamoun P (1995) Metabolism of citrulline in man. Amino Acids. https://doi.org/10.1007/BF00807268
59. Wu G, Brosnan JT (1992) Macrophages can convert citrulline into arginine. Biochem J. https://doi.org/10.1042/bj2810045

60. Nussler AK, Billiar TR, Liu ZZ, Morris SM (1994) Coinduction of nitric oxide synthase and argininosuccinate synthetase in a murine macrophage cell line implications for regulation of nitric oxide production. J Biol Chem 269:1257-1261

61. Baydoun AR, Emery PW, Pearson JD, Mann GE (1990) Substrate-dependent regulation of intracellular amino acid concentrations in cultured bovine aortic endothelial cells. Biochem Biophys Res Commun. https://doi.org/10.1016/S0006-291X(05) 80876-9

62. Bogle RG, MacAllister RJ, Whitley GSJ, Vallance P (1995) Induction of $N(\mathrm{G})$-monomethyl-L-arginine uptake: a mechanism for differential inhibition of NO synthases? Am J Physiol—Cell Physiol 269:C750-C756

63. Böger RH et al (2000) LDL cholesterol upregulates synthesis of asymmetrical dimethylarginine in human endothelial cells: involvement of $S$-adenosylmethionine-dependent methyltransferases. Circ Res. https://doi.org/10.1161/01.RES.87.2.99

64. Topal G, Brunet A, Walch L, Boucher J-L, David-Dufilho M (2006) Mitochondrial arginase II modulates nitric-oxide synthesis through nonfreely exchangeable L-arginine pools in human endothelial cells. J Pharmacol Exp Ther 318:1368-1374

65. Palacín M, Estévez R, Bertran J, Zorzano A (1998) Molecular biology of mammalian plasma membrane amino acid transporters. Physiol Rev. https://doi.org/10.1152/physrev.1998.78.4.969

66. Closs EI (1996) CATs, a family of three distinct mammalian cationic amino acid transporters. Amino Acids. https://doi.org/ 10.1007/BF00813860

67. Devés R, Boyd CAR (1998) Transporters for cationic amino acids in animal cells: discovery, structure, and function. Physiol Rev. https://doi.org/10.1152/physrev.1998.78.2.487

68. Closs EI, Boissel JP, Habermeier A, Rotmann A (2006) Structure and function of cationic amino acid transporters (CATs). J Membr Biol. https://doi.org/10.1007/s00232-006-0875-7

69. Closs EI, Gräf P, Habermeier A, Cunningham JM, Förstermann U (1997) Human cationic amino acid transporters hCAT-1, hCAT-2A, and hCAT-2B: three related carriers with distinct transport properties. Biochem. https://doi.org/10.1021/bi962 $829 \mathrm{p}$

70. Jungnickel KEJ, Parker JL, Newstead S (2018) Structural basis for amino acid transport by the CAT family of SLC7 transporters. Nat Commun. https://doi.org/10.1038/s41467-018-03066-6

71. Bogle RG, Moncada S, Pearson JD, Mann GE (1992) Identification of inhibitors of nitric oxide synthase that do not interact with the endothelial cell L-arginine transporter. Br J Pharmacol. https://doi.org/10.1111/j.1476-5381.1992.tb09053.x

72. Schmidt K, Klatt P, Mayer B (1993) Characterization of endothelial cell amino acid transport systems involved in the actions of nitric oxide synthase inhibitors. Mol Pharmacol 44:615-621

73. DeGeorge GL, Heck DE, Laskin JD (1997) Arginine metabolism in keratinocytes and macrophages during nitric oxide biosynthesis. Biochem Pharmacol. https://doi.org/10.1016/S00062952(97)00144-5

74. Rodriguez PC et al (2004) Arginase I production in the tumor microenvironment by mature myeloid cells inhibits T-cell receptor expression and antigen-specific T-cell responses. Cancer Res 64:5839-5849

75. MacLeod CL, Kakuda DK (1996) Regulation of CAT: cationic amino acid transporter gene expression. Amino Acids. https:// doi.org/10.1007/BF00813859

76. Kakuda DK, Finley KD, Maruyama M, MacLeod CL (1998) Stress differentially induces cationic amino acid transporter gene expression. Biochim Biophys Acta-Biomembr. https:// doi.org/10.1016/S0005-2736(98)00155-2 
77. Cendan JC, Souba WW, Copeland EM, Lind DS (1995) Characterization and growth factor stimulation of L-arginine transport in a human colon cancer cell line. Ann Surg Oncol. https:// doi.org/10.1007/BF02307033

78. Cendan JC et al (1996) Inflammatory mediators stimulate arginine transport and arginine-derived nitric oxide production in a murine breast cancer cell line. J Surg Res. https://doi.org/10. 1006/jsre.1996.0044

79. Porcelli V, Fiermonte G, Longo A, Palmieri F (2014) The human gene SLC25A29, of solute carrier family 25, encodes a mitochondrial transporter of basic amino acids. J Biol Chem. https://doi.org/10.1074/jbc.M114.547448

80. Kim HS, Cha SY, Jo CH, Han A, Hwang KY (2014) The crystal structure of arginyl-tRNA synthetase from Homo sapiens. FEBS Lett. https://doi.org/10.1016/j.febslet.2014.05.027

81. Ferber S, Ciechanover A (1987) Role of arginine-tRNA in protein degradation by the ubiquitin pathway. Nature. https://doi. org/10.1038/326808a0

82. Vockley JG et al (1996) Cloning and characterization of the human type II arginase gene. Genomics 38:118-123

83. Gotoh T et al (1996) Molecular cloning of cDNA for nonhepatic mitochondrial arginase (arginase II) and comparison of its induction with nitric oxide synthase in a murine macrophage-like cell line. FEBS Lett 395:119-122

84. Jenkinson CP, Grody WW, Cederbaum SD (1996) Comparative properties of arginases. Comp Biochem Physiol B 114:107-132

85. Morris SM (2010) Arginine: master and commander in innate immune responses. Sci Signal 3:1-5

86. Nong Z, Hoylaerts M, Van Pelt N, Collen D, Janssens S (1997) Nitric oxide inhalation inhibits platelet aggregation and plateletmediated pulmonary thrombosis in rats. Circ Res. https://doi.org/ 10.1161/01.RES.81.5.865

87. Hickey MJ, Kubes P (1999) Nitric oxide and leukocyte adhesion: experience with NO inhibitors, NO donors and iNOS-deficient mice. Shock, sepsis, and organ failure. Springer, Heidelberg

88. Baek KJ, Thiel BA, Lucas S, Stuehr DJ (1993) Macrophage nitric oxide synthase subunits. Purification, characterization, and role of prosthetic groups and substrate in regulating their association into a dimeric enzyme. J Biol Chem 268:21120-21129

89. Vos TA et al (1997) Differential effects of nitric oxide synthase inhibitors on endotoxin-induced liver damage in rats. Gastroenterol. https://doi.org/10.1053/gast.1997.v113.pm9322528

90. Kimura $\mathrm{H}$ et al (1998) Increased expression of an inducible isoform of nitric oxide synthase and the formation of peroxynitrite in colonic mucosa of patients with active ulcerative colitis. Gut. https://doi.org/10.1136/gut.42.2.180

91. Forrester K et al (1996) Nitric oxide-induced p53 accumulation and regulation of inducible nitric oxide synthase expression by wild-type p53. Proc Natl Acad Sci USA. https://doi.org/10.1073/ pnas.93.6.2442

92. Murphy MP (1999) Nitric oxide and cell death. Biochim Biophys Acta. https://doi.org/10.1016/S0005-2728(99)00029-8

93. Sarti P, Forte E, Mastronicola D, Giuffrè A, Arese M (2012) Cytochrome c oxidase and nitric oxide in action: molecular mechanisms and pathophysiological implications. Biochim Biophys Acta. https://doi.org/10.1016/j.bbabio.2011.09.002

94. Griffith OW, Stuehr DJ (1995) Nitric oxide synthases: properties and catalytic mechanism. Annu Rev Physiol. https://doi.org/10. 1146/annurev.ph.57.030195.003423

95. Lee J, Ryu H, Ferrante RJ, Morris SM, Ratan RR (2003) Translational control of inducible nitric oxide synthase expression by arginine can explain the arginine paradox. Proc Natl Acad Sci USA 100:4843-4848

96. Fligger J, Blum J, Jungi TW (1999) Induction of intracellular arginase activity does not diminish the capacity of macrophages to produce nitric oxide in vitro. Immunobiology 200:169-186

97. Förstermann U et al (1994) Nitric oxide synthase isozymes. Characterization, purification, molecular cloning, and functions. Hypertension 23:1121-1131

98. Daghigh F, Fukuto JM, Ash DE (1994) Inhibition of rat liver arginase by an intermediate in NO biosynthesis, NG-hydroxyL-arginine: implications for the regulation of nitric oxide biosynthesis by arginase. Biochem Biophys Res Commun. https:// doi.org/10.1006/bbrc.1994.1909

99. Wyss M, Kaddurah-Daouk R (2000) Creatine and creatinine metabolism. Physiol Rev. https://doi.org/10.1152/physrev. 2000.80.3.1107

100. Morris SM (2007) Arginine metabolism: boundaries of our knowledge. J Nutr 137:1602S-1609S

101. Li G et al (1994) Agmatine: an endogenous clonidine-displacing substance in the brain. Science 263:966-969

102. Morrissey J, Mccracken R, Ishidoya S, Klahr S (1995) Partial cloning and characterization of an arginine decarboxylase in the kidney. Kidney Int 47:1458-1461

103. Lortie MJ et al (1996) Agmatine, a bioactive metabolite of arginine: production, degradation, and functional effects in the kidney of the rat. J Clin Invest 97:413-420

104. Sastre M, Galea E, Feinstein D, Reis DJ, Regunathan S (1998) Metabolism of agmatine in macrophages: modulation by lipopolysaccharide and inhibitory cytokines. Biochem $\mathrm{J}$ 330:1405-1409

105. Noël W, Raes G, Ghassabeh GH, De Baetselier P, Beschin A (2004) Alternatively activated macrophages during parasite infections. Trends Parasitol. https://doi.org/10.1016/j.pt.2004. 01.004

106. Gordon S (2003) Alternative activation of macrophages. Nat Rev Immunol. https://doi.org/10.1038/nri978

107. Gallina $\mathrm{G}$ et al (2006) Tumors induce a subset of inflammatory monocytes with immunosuppressive activity on $\mathrm{CD} 8^{+} \mathrm{T}$ cells. $\mathrm{J}$ Clin Invest 116:2777-2790

108. Lumeng CN, Bodzin JL, Saltiel AR (2007) Obesity induces a phenotypic switch in adipose tissue macrophage polarization. $\mathrm{J}$ Clin Invest 117:175-184

109. Thomas AC, Mattila JT (2014) 'Of mice and men': arginine metabolism in macrophages. Frontiers Immunol 5:479

110. Bronte V, Serafini P, Mazzoni A, Segal DM, Zanovello P (2003) L-Arginine metabolism in myeloid cells controls T-lymphocyte functions. Trends Immunol 24:301-305

111. Louis CA et al (1998) Distinct arginase isoforms expressed in primary and transformed macrophages: regulation by oxygen tension. Am J Physiol. https://doi.org/10.1152/ajpregu.1998.274.3. r775

112. Buga GM et al (1996) Arginase activity in endothelial cells: inhibition by $N(\mathrm{G})$-hydroxy-L- arginine during high-output NO production. Am J Physiol. https://doi.org/10.1152/ajpheart.1996. 271.5.h1988

113. Louis CA, Mody V, Henry WL, Reichner JS, Albina JE (1999) Regulation of arginase isoforms I and II by IL-4 in cultured murine peritoneal macrophages. Am J Physiol 276:R237-R242

114. Fernández-Ruiz V, López-Moratalla N, González A (2005) Production of nitric oxide and self-nitration of proteins during monocyte differentiation to dendritic cells. J Physiol Biochem 61:517-525

115. Ji L et al (2019) Slc6a8-mediated creatine uptake and accumulation reprogram macrophage polarization via regulating cytokine responses article Slc6a8-mediated creatine uptake and accumulation reprogram macrophage polarization via regulating cytokine responses. Immunity 51:272-284.e7 
116. Kim JH, Kim JY, Mun CH, Suh M, Lee JE (2017) Agmatine modulates the phenotype of macrophage acute phase after spinal cord injury in rats. Exp Neurobiol 26:278-286

117. Regunathan S, Piletz JE (2003) Regulation of inducible nitric oxide synthase and agmatine synthesis in macrophages and astrocytes. Ann New York Academy Sci 1009:20-29 (New York Academy of Sciences)

118. Chai J et al (2016) Agmatine reduces lipopolysaccharidemediated oxidant response via activating PI3K/Akt pathway and up-regulating Nrf2 and HO-1 expression in macrophages. PLoS ONE 11:e0163634

119. Arias $M$ et al (1997) Inhibition of virulent Mycobacterium tuberculosis by $\mathrm{Bcg}(\mathrm{r})$ and $\mathrm{Bcg}(\mathrm{s})$ macrophages correlates with nitric oxide production. J Infect Dis. https://doi.org/10.1086/ 514154

120. Gross A et al (1998) Expression and bactericidal activity of nitric oxide synthase in Brucella suis-infected murine macrophages. Infect Immun. https://doi.org/10.1128/iai.66.4.1309-1316.1998

121. Silva JS, Vespa GNR, Cardoso MAG, Aliberti JCS, Cunha FQ (1995) Tumor necrosis factor alpha mediates resistance to Trypanosoma cruzi infection in mice by inducing nitric oxide production in infected gamma interferon-activated macrophages. Infect Immun. https://doi.org/10.1128/iai.63.12.4862-4867.1995

122. Miyagi K, Kawakami K, Saito A (1997) Role of reactive nitrogen and oxygen intermediates in gamma interferon-stimulated murine macrophage bactericidal activity against Burkholderia pseudomallei. Infect Immun. https://doi.org/10.1128/iai.65.10. 4108-4113.1997

123. Kleinert $\mathrm{H}$ et al (1998) Cytokine induction of NO synthase II in human DLD-1 cells: roles of the JAK-STAT, AP-1 and NF- $\mathrm{kB}-$ signaling pathways. Br J Pharmacol. https://doi.org/10.1038/sj. bjp.0702039

124. Ganster RW, Taylor BS, Shao L, Geller DA (2001) Complex regulation of human inducible nitric oxide synthase gene transcription by Stat 1 and NF- $\kappa$ B. Proc Natl Acad Sci USA. https:// doi.org/10.1073/pnas. 151239498

125. Modolell M, Corraliza IM, Link F, Soler G, Eichmann K (1995) Reciprocal regulation of the nitric oxide synthase/arginase balance in mouse bone marrow-derived macrophages by TH 1 and TH 2 cytokines. Eur J Immunol. https://doi.org/10.1002/eji. 1830250436

126. Martin E, Nathan C, Xie QW (1994) Role of interferon regulatory factor 1 in induction of nitric oxide synthase. J Exp Med. https://doi.org/10.1084/jem.180.3.977

127. Wiesinger $\mathrm{H}$ (2001) Arginine metabolism and the synthesis of nitric oxide in the nervous system. Prog Neurobiol 64:365-391

128. Kakuda DK, Sweet MJ, MacLeod CL, Hume DA, Markovich D (1999) CAT2-mediated L-arginine transport and nitric oxide production in activated macrophages. Biochem J. https://doi.org/ 10.1042/0264-6021:3400549

129. Sakai N, Kaufman S, Milstien S (1995) Parallel induction of nitric oxide and tetrahydrobiopterin synthesis by cytokines in rat glial cells. J Neurochem. https://doi.org/10.1046/j.1471-4159. 1995.65020895.x

130. Nussler AK et al (1996) A cohort of supporting metabolic enzymes is coinduced with nitric oxide synthase in human tumor cell lines. Cancer Lett. https://doi.org/10.1016/0304-3835(96) 04199-7

131. Frank S, Madlener M, Pfeilschifter J, Werner S (1998) Induction of inducible nitric oxide synthase and its corresponding tetrahydrobiopterin-cofactor-synthesizing enzyme GTP-cyclohydrolase I during cutaneous wound repair. J Invest Dermatol. https://doi. org/10.1046/j.1523-1747.1998.00434.x

132. García-Nogales P, Almeida A, Fernández E, Medina JM, Bolaños JP (1999) Induction of glucose-6-phosphate dehydrogenase by lipopolysaccharide contributes to preventing nitric oxide-mediated glutathione depletion in cultured rat astrocytes. J Neurochem. https://doi.org/10.1046/j.1471-4159.1999.721750.x

133. Qualls JE et al (2012) Sustained generation of nitric oxide and control of mycobacterial infection requires argininosuccinate synthase 1. Cell Host Microbe 12:313-323

134. Vasquez-Dunddel D et al (2013) STAT3 regulates arginase-i in myeloid-derived suppressor cells from cancer patients. J Clin Invest. https://doi.org/10.1172/JCI60083

135. Gray MJ, Poljakovic M, Kepka-Lenhart D, Morris SM (2005) Induction of arginase I transcription by IL-4 requires a composite DNA response element for STAT6 and C/EBP $\beta$. Gene. https:// doi.org/10.1016/j.gene.2005.04.004

136. Pauleau A-L et al (2004) Enhancer-mediated control of macrophage-specific arginase I expression. J Immunol 172:7565-7573

137. Qualls JE et al (2010) Arginine usage in mycobacteria-infected macrophages depends on autocrine-paracrine cytokine signaling. Sci Signal. https://doi.org/10.1126/scisignal.2000955

138. Munder M et al (1999) Th1/Th2-regulated expression of arginase isoforms in murine macrophages and dendritic cells. J Immunol 163:3771-3777

139. Rodriguez PC et al (2005) Arginase I in myeloid suppressor cells is induced by COX-2 in lung carcinoma. J Exp Med 202:931-939

140. Bernard AC et al (2000) Beta adrenoceptor regulation of macrophage arginase activity. Surgery. https://doi.org/10.1067/msy. 2000.104115

141. Zheng S, McElwain CM, Taffet SM (1991) Regulation of mouse ornithine decarboxylase gene expression in a macrophage-like cell line: synergistic induction by bacterial lipopolysaccharide and camp. Biochem Biophys Res Commun. https://doi.org/10. 1016/S0006-291X(05)81198-2

142. Morris SM, Kepka-Lenhart D, Chen LIC (1998) Differential regulation of arginases and inducible nitric oxide synthase in murine macrophage cells. Am J Physiol. https://doi.org/10.1152/ ajpendo.1998.275.5.e740

143. Barron L et al (2013) Role of arginase 1 from myeloid cells in Th2-dominated lung inflammation. PLoS ONE. https://doi.org/ 10.1371/journal.pone.0061961

144. Campbell L, Saville CR, Murray PJ, Cruickshank SM, Hardman MJ (2013) Local arginase 1 activity is required for cutaneous wound healing. J Invest Dermatol. https://doi.org/10.1038/jid. 2013.164

145. Shearer JD, Richards JR, Mills CD, Caldwell MD (1997) Differential regulation of macrophage arginine metabolism: a proposed role in wound healing. Am J Physiol 272:181-190

146. Albina JE, Abate JA, Mastrofrancesco B (1993) Role of ornithine as a proline precursor in healing wounds. J Surg Res. https://doi. org/10.1006/jsre.1993.1114

147. Albina JE, Mills CD, Henry WL, Caldwell MD (1990) Temporal expression of different pathways of $\mathrm{L}$-arginine metabolism in healing wounds. J Immunol 144:3877-3880

148. Esser-von Bieren J et al (2013) Antibodies trap tissue migrating helminth larvae and prevent tissue damage by driving IL-4R $\alpha$ independent alternative differentiation of macrophages. PLoS Pathog. https://doi.org/10.1371/journal.ppat.1003771

149. Bussière FI et al (2005) Spermine causes loss of innate immune response to Helicobacter pylori by inhibition of inducible nitricoxide synthase translation. J Biol Chem. https://doi.org/10.1074/ jbc.C400498200

150. Mössner J, Hammermann R, Racké K (2001) Concomitant downregulation of L-arginine transport and nitric oxide (NO) synthesis in rat alveolar macrophages by the polyamine spermine. Pulm Pharmacol Ther. https://doi.org/10.1006/pupt.2001.0297

151. Pesce JT et al (2009) Arginase-1-expressing macrophages suppress Th2 cytokine-driven inflammation and fibrosis. PLoS Pathog. https://doi.org/10.1371/journal.ppat.1000371 
152. Herbert DR et al (2010) Arginase I suppresses IL-12/IL23p40-driven intestinal inflammation during acute schistosomiasis. J Immunol. https://doi.org/10.4049/jimmunol.0902009

153. Mattila JT et al (2013) Microenvironments in tuberculous granulomas are delineated by distinct populations of macrophage subsets and expression of nitric oxide synthase and arginase isoforms. J Immunol. https://doi.org/10.4049/jimmunol.13001 13

154. Monin L et al (2015) Helminth-induced arginase-1 exacerbates lung inflammation and disease severity in tuberculosis. J Clin Invest. https://doi.org/10.1172/JCI77378

155. El Kasmi KC et al (2008) Toll-like receptor-induced arginase 1 in macrophages thwarts effective immunity against intracellular pathogens. Nat Immunol 9:1399-1406

156. Gobert AP et al (2001) Helicobacter pylori arginase inhibits nitric oxide production by eukaryotic cells: a strategy for bacterial survival. Proc Natl Acad Sci 98:13844-13849

157. Kapp K et al (2014) Granulocyte functions are independent of arginine availability. J Leukoc Biol. https://doi.org/10.1189/ jlb.3ab0214-082r

158. Munder M et al (2006) Suppression of T-cell functions by human granulocyte arginase. Blood 108:1627-1634

159. Jacobsen LC, Theilgaard-Mönch K, Christensen EI, Borregaard $\mathrm{N}$ (2007) Arginase 1 is expressed in myelocytes/metamyelocytes and localized in gelatinase granules of human neutrophils. Blood. https://doi.org/10.1182/blood-2006-06-032599

160. Rotondo $\mathrm{R}$ et al (2011) Exocytosis of azurophil and arginase 1-containing granules by activated polymorphonuclear neutrophils is required to inhibit $\mathrm{T}$ lymphocyte proliferation. $\mathrm{J}$ Leukoc Biol. https://doi.org/10.1189/jlb.1109737

161. Darcy CJ et al (2014) Neutrophils with myeloid derived suppressor function deplete arginine and constrain $\mathrm{T}$ cell function in septic shock patients. Crit Care. https://doi.org/10.1186/ cc14003

162. Sakiniene E, Bremell T, Tarkowski A (1997) Inhibition of nitric oxide synthase (NOS) aggravates Staphylococcus aureus septicaemia and septic arthritis. Clin Exp Immunol. https://doi. org/10.1046/j.1365-2249.1997.4431456.x

163. Nagarkoti S et al (2019) L-Arginine and tetrahydrobiopterin supported nitric oxide production is crucial for the microbicidal activity of neutrophils. Free Radic Res. https://doi.org/ 10.1080/10715762.2019.1566605

164. Ródenas J, Mitjavila MT, Carbonell T (1998) Nitric oxide inhibits superoxide production by inflammatory polymorphonuclear leukocytes. Am J Physiol. https://doi.org/10.1152/ajpce 11.1998.274.3.c827

165. Nath J, Powledge A (1997) Modulation of human neutrophil inflammatory responses by nitric oxide: studies in unprimed and LPS-primed cells. J Leukoc Biol. https://doi.org/10.1002/ jlb.62.6.805

166. Ostrand-Rosenberg S, Fenselau C (2018) Myeloid-derived suppressor cells: immune-suppressive cells that impair antitumor immunity and are sculpted by their environment. J Immunol. https://doi.org/10.4049/jimmunol.1701019

167. Serafini P, Borrello I, Bronte V (2006) Myeloid suppressor cells in cancer: recruitment, phenotype, properties, and mechanisms of immune suppression. Semin Cancer Biol. https://doi. org/10.1016/j.semcancer.2005.07.005

168. Brys L et al (2005) Reactive oxygen species and 12/15-lipoxygenase contribute to the antiproliferative capacity of alternatively activated myeloid cells elicited during helminth infection. J Immunol. https://doi.org/10.4049/jimmunol.174.10. 6095

169. Mazzoni A et al (2002) Myeloid suppressor lines inhibit $\mathrm{T}$ cell responses by an NO-dependent mechanism. J Immunol. https:// doi.org/10.4049/jimmunol.168.2.689
170. Tsuei BJ et al (2001) Surgery induces human mononuclear cell arginase 1 expression. J Trauma. https://doi.org/10.1097/00005 373-200109000-00012

171. Ochoa JB et al (2001) Arginase I expression and activity in human mononuclear cells after injury. Ann Surg. https://doi. org/10.1097/00000658-200103000-00014

172. Makarenkova VP, Bansal V, Matta BM, Perez LA, Ochoa JB (2006) CD11b + /Gr-1 + myeloid suppressor cells cause T cell dysfunction after traumatic stress. J Immunol. https://doi.org/ 10.4049/jimmunol.176.4.2085

173. Bronte V et al (2003) IL-4-induced arginase 1 suppresses alloreactive $\mathrm{T}$ cells in tumor-bearing mice. J Immunol 170:270-278

174. Zea AH et al (2005) Arginase-producing myeloid suppressor cells in renal cell carcinoma patients: a mechanism of tumor evasion. Cancer Res 65:3044-3048

175. Bronte $\mathrm{V}$ et al (2005) Boosting antitumor responses of $\mathrm{T}$ lymphocytes infiltrating human prostate cancers. J Exp Med 201:1257-1268

176. Kusmartsev S, Gabrilovich DI (2006) Role of immature myeloid cells in mechanisms of immune evasion in cancer. Cancer Immunol Immunother 55:237-245

177. Rutschman R et al (2001) Cutting edge: Stat6-dependent substrate depletion regulates nitric oxide production. J Immunol 166:2173-2177

178. Serafini P, Mgebroff S, Noonan K, Borrello I (2008) Myeloidderived suppressor cells promote cross-tolerance in B-cell lymphoma by expanding regulatory T cells. Cancer Res. https://doi. org/10.1158/0008-5472.CAN-07-6621

179. Rodriguez PC et al (2003) L-Arginine consumption by macrophages modulates the expression of $\mathrm{CD} 3$ chain in T lymphocytes. J Immunol 171:1232-1239

180. Verrey F et al (2004) CATs and HATs: The SLC7 family of amino acid transporters. Pflugers Arch. https://doi.org/10.1007/ s00424-003-1086-z

181. Kaneko $S$ et al (2007) Ornithine transport via cationic amino acid transporter- 1 is involved in ornithine cytotoxicity in retinal pigment epithelial cells. Investig Ophthalmol Vis Sci. https://doi. org/10.1167/iovs.06-0398

182. White AR et al (2006) Knockdown of arginase I restores NO signaling in the vasculature of old rats. Hypertension. https:// doi.org/10.1161/01.HYP.0000198543.34502.d7

183. Xia Y, Zweier JL (1997) Superoxide and peroxynitrite generation from inducible nitric oxide synthase in macrophages. Proc Natl Acad Sci USA. https://doi.org/10.1073/pnas.94.13.6954

184. Xia Y, Roman LJ, Masters BSS, Zweier JL (1998) Inducible nitric-oxide synthase generates superoxide from the reductase domain. J Biol Chem. https://doi.org/10.1074/jbc.273.35.22635

185. Takahashi A et al (2005) Preferential cell death of $\mathrm{CD} 8^{+}$effector memory (CCR7 - CD45RA - ) T cells by hydrogen peroxideinduced oxidative stress. J Immunol. https://doi.org/10.4049/ jimmunol.174.10.6080

186. Case AJ et al (2011) Elevated mitochondrial superoxide disrupts normal $\mathrm{T}$ cell development, impairing adaptive immune responses to an influenza challenge. Free Radic Biol Med. https:// doi.org/10.1016/j.freeradbiomed.2010.11.025

187. Kesarwani P, Murali AK, Al-Khami AA, Mehrotra S (2013) Redox regulation of T-cell function: from molecular mechanisms to significance in human health and disease. Antioxid Redox Signal. https://doi.org/10.1089/ars.2011.4073

188. Nagaraj $S$ et al (2007) Altered recognition of antigen is a mechanism of $\mathrm{CD}^{+} \mathrm{T}$ cell tolerance in cancer. Nat Med. https://doi. org/10.1038/nm1609

189. Molon B et al (2011) Chemokine nitration prevents intratumoral infiltration of antigen-specific T cells. J Exp Med. https://doi.org/ $10.1084 /$ jem. 20101956 
190. Lee DH et al (2016) Glutathione peroxidase 1 deficiency attenuates concanavalin A-induced hepatic injury by modulation of T-cell activation. Cell Death Dis. https://doi.org/10.1038/cddis. 2016.95

191. Baniyash M (2004) TCR $\zeta$-chain downregulation: curtailing an excessive inflammatory immune response. Nat Rev Immunol. https://doi.org/10.1038/nri1434

192. Macagno A, Napolitani G, Lanzavecchia A, Sallusto F (2007) Duration, combination and timing: the signal integration model of dendritic cell activation. Trends Immunol. https://doi.org/ 10.1016/j.it.2007.03.008

193. Banchereau J, Steinman RM (1998) Dendritic cells and the control of immunity. Nature. https://doi.org/10.1038/32588

194. Dunand-Sauthier I et al (2011) Silencing of c-Fos expression by microRNA-155 is critical for dendritic cell maturation and function. Blood 117:4490-4500

195. Liscovsky MV et al (2009) Interferon- $\gamma$ priming is involved in the activation of arginase by oligodeoxinucleotides containing $\mathrm{CpG}$ motifs in murine macrophages. Immunology. https://doi. org/10.1111/j.1365-2567.2008.02938.x

196. Dunand-Sauthier I et al (2014) Repression of arginase-2 expression in dendritic cells by microRNA-155 is critical for promoting T cell proliferation. J Immunol 193:1690-1700

197. Geissmann F et al (2008) Blood monocytes: distinct subsets, how they relate to dendritic cells, and their possible roles in the regulation of T-cell responses. Immunol Cell Biol. https:// doi.org/10.1038/icb.2008.19

198. Serbina NV, Salazar-Mather TP, Biron CA, Kuziel WA, Pamer EG (2003) TNF/iNOS-producing dendritic cells mediate innate immune defense against bacterial infection. Immunity. https:// doi.org/10.1016/S1074-7613(03)00171-7

199. Copin R, De Baetselier P, Carlier Y, Letesson J-J, Muraille E (2007) MyD88-dependent activation of B220-CD11b+LY$6 \mathrm{C}+$ dendritic cells during Brucella melitensis infection. J Immunol. https://doi.org/10.4049/jimmunol.178.8.5182

200. De Trez C et al (2009) iNOS-producing inflammatory dendritic cells constitute the major infected cell type during the chronic Leishmania major infection phase of C57BL/6 resistant mice. PLoS Pathog. https://doi.org/10.1371/journal.ppat.1000494

201. Marigo I et al (2016) T cell cancer therapy requires CD40CD40L activation of tumor necrosis factor and inducible nitricoxide-synthase-producing dendritic cells. Cancer Cell. https:// doi.org/10.1016/j.ccell.2016.08.004

202. Kania $G$ et al (2013) Innate signaling promotes formation of regulatory nitric oxide-producing dendritic cells limiting T-cell expansion in experimental autoimmune myocarditis. Circulation. https://doi.org/10.1161/CIRCULATIONAHA.112.000434

203. Guilliams $M$ et al (2009) IL-10 dampens TNF/inducible nitric oxide synthase-producing dendritic cell-mediated pathogenicity during parasitic infection. J Immunol. https://doi.org/10. 4049/jimmunol.182.2.1107

204. Mondanelli $\mathrm{G}$ et al (2017) A relay pathway between arginine and tryptophan metabolism confers immunosuppressive properties on dendritic cells. Immunity 46:233-244

205. McGovern N et al (2017) Human fetal dendritic cells promote prenatal T-cell immune suppression through arginase-2. Nature 546:662-666

206. Yang J, Gonon AT, Sjöquist PO, Lundberg JO, Pernow J (2013) Arginase regulates red blood cell nitric oxide synthase and export of cardioprotective nitric oxide bioactivity. Proc Natl Acad Sci USA. https://doi.org/10.1073/pnas.1307058110

207. Kim PS et al (2002) Expression of the liver form of arginase in erythrocytes. Mol Genet Metab. https://doi.org/10.1016/ S1096-7192(02)00034-3
208. Delyea C et al (2018) CD71+ erythroid suppressor cells promote fetomaternal tolerance through arginase-2 and PDL-1. J Immunol. https://doi.org/10.4049/jimmunol.1800113

209. Elahi $S$ et al (2013) Immunosuppressive CD71+ erythroid cells compromise neonatal host defence against infection. Nature 504:158-162

210. Dunsmore G et al (2017) Erythroid suppressor cells compromise neonatal immune response against bordetella pertussis. J Immunol. https://doi.org/10.4049/jimmunol.1700742

211. Namdar A et al (2017) CD71+ erythroid suppressor cells impair adaptive immunity against bordetella pertussis. Sci Rep. https://doi.org/10.1038/s41598-017-07938-7

212. Hsueh EC et al (2012) Deprivation of arginine by recombinant human arginase in prostate cancer cells. J Hematol Oncol. https://doi.org/10.1186/1756-8722-5-17

213. Peters H, Border WA, Noble NA (1999) L-Arginine supplementation increases mesangial cell injury and subsequent tissue fibrosis in experimental glomerulonephritis. Kidney Int. https://doi.org/10.1046/j.1523-1755.1999.00462.x

214. Popovic PJ, Ochoa JB (2007) Arginine and immunity 1-3. J Nutr 137:1681-1686

215. Martí i Líndez A-AA, et al (2019) Mitochondrial arginase-2 is a cell-autonomous regulator of $\mathrm{CD} 8+\mathrm{T}$ cell function and antitumor efficacy. JCI Insight 4(24):e132975. https://doi.org/ 10.1172/jci.insight. 132975

216. Ochoa JB et al (2001) Effects of L-arginine on the proliferation of T lymphocyte subpopulations. J Parenter Enter Nutr 25:23-29

217. Barbul A et al (1985) Intravenous hyperalimentation with high arginine levels improves wound healing and immune function. $\mathrm{J}$ Surg Res 38:328-334

218. Calder PC, Yaqoob P 2003 Amino acids and immune function. Metabolic and Therapeutic Aspects of Amino Acids in Clinical Nutrition, 2nd Edn

219. Weissman AM et al (1988) Tyrosine phosphorylation of the human $\mathrm{T}$ cell antigen receptor zeta-chain: activation via $\mathrm{CD} 3$ but not CD2. J Immunol. 141:3532-3536

220. Rodriguez PC et al (2002) Regulation of T cell receptor CD3zeta chain expression by L-arginine. J Biol Chem 277:21123-21129

221. Minami Y, Weissman AM, Samelson LE, Klausner RD (1987) Building a multichain receptor: synthesis, degradation, an assembly of the T-cell antigen receptor. Proc Natl Acad Sci USA. https://doi.org/10.1073/pnas.84.9.2688

222. Kwon H, Spencer TE, Bazer FW, Wu G (2003) Developmental changes of amino acids in ovine fetal fluids. Biol Reprod. https:// doi.org/10.1095/biolreprod.102.012971

223. Bansal V et al (2004) Citrulline can preserve proliferation and prevent the loss of $\mathrm{CD} 3 \zeta$ chain under conditions of low arginine. J Parenter Enter Nutr. https://doi.org/10.1177/014860710402800 6423

224. Grzywa TM et al (2020) Myeloid cell-derived arginase in cancer immune response. Front Immunol 11:938

225. Zabaleta J et al (2004) Helicobacter pylori arginase inhibits $\mathrm{T}$ cell proliferation and reduces the expression of the TCR zeta-chain (CD3zeta). J Immunol 173:586-593

226. Feldmeyer $\mathrm{N}$ et al (2012) Arginine deficiency leads to impaired cofilin dephosphorylation in activated human T lymphocytes. Int Immunol. https://doi.org/10.1093/intimm/dxs004

227. Ghosh $\mathrm{M}$ et al (2004) Cofilin promotes actin polymerization and defines the direction of cell motility. Science. https://doi.org/10. 1126/science.1094561 (80)

228. Huang Y, Burkhardt JK (2007) T-cell-receptor-dependent actin regulatory mechanisms. J Cell Sci. https://doi.org/10.1242/jcs. 000786 
229. Zea AH et al (2004) L-Arginine modulates CD3 $\zeta$ expression and $\mathrm{T}$ cell function in activated human T lymphocytes. Cell Immunol 232:21-31

230. Kato JY (1997) Control of G1 progression by D-type cyclins: key event for cell proliferation. Leukemia 11(Suppl 3):347-351

231. Rodriguez PC et al (2010) L-Arginine deprivation regulates cyclin D3 mRNA stability in human T cells by controlling HuR expression. J Immunol 185:5198-5204

232. Rodriguez PC, Quiceno DG, Ochoa AC (2007) L-Arginine availability regulates T-lymphocyte cell-cycle progression. Blood 109:1568-1573

233. Holcik M, Sonenberg N (2005) Translational control in stress and apoptosis. Nat Rev Mol Cell Biol 6:318-327

234. Fallarino F et al (2006) The combined effects of tryptophan starvation and tryptophan catabolites down-regulate $\mathrm{T}$ cell receptor $\zeta$-chain and induce a regulatory phenotype in naive $\mathrm{T}$ cells. $\mathrm{J}$ Immunol 176:6752-6761

235. Munn DH et al (2005) GCN2 kinase in T cells mediates proliferative arrest and anergy induction in response to indoleamine 2,3-dioxygenase. Immunity 22:633-642

236. Morrow K et al (2013) Anti-leukemic mechanisms of pegylated arginase I in acute lymphoblastic T-cell leukemia. Leukemia 27:569-577

237. Fletcher $\mathrm{M}$ et al (2015) L-Arginine depletion blunts antitumor T-cell responses by inducing myeloid-derived suppressor cells. Cancer Res 75:275-283

238. Fultang L et al (2020) Metabolic engineering against the arginine microenvironment enhances CAR-T cell proliferation and therapeutic activity. Blood. https://doi.org/10.1182/blood.20190 04500

239. Lowe $\mathrm{MM}$ et al (2019) Regulatory $\mathrm{T}$ cells use arginase 2 to enhance their metabolic fitness in tissues. JCI Insight. https:// doi.org/10.1172/jci.insight. 129756

240. Saio M, Radoja S, Marino M, Frey AB (2001) Tumor-infiltrating macrophages induce apoptosis in activated CD8+ T cells by a mechanism requiring cell contact and mediated by both the cellassociated form of TNF and nitric oxide. J Immunol. https://doi. org/10.4049/jimmunol.167.10.5583

241. Hildeman DA et al (1999) Reactive oxygen species regulate activation-induced $\mathrm{T}$ cell apoptosis. Immunity 10:735-744

242. Hildeman DA et al (2003) Control of Bcl-2 expression by reactive oxygen species. Proc Natl Acad Sci USA 100:15035-15040

243. Vig $M$ et al (2004) Inducible nitric oxide synthase in $\mathrm{T}$ cells regulates $\mathrm{T}$ cell death and immune memory. $\mathrm{J}$ Clin Invest 113:1734-1742

244. Fischer TA et al (2001) Activation of cGMP-dependent protein kinase $\mathrm{I} \beta$ inhibits interleukin 2 release and proliferation of $\mathrm{T}$ cell receptor-stimulated human peripheral T cells. J Biol Chem. https://doi.org/10.1074/jbc.M009781200

245. Macphail SE et al (2003) Nitric oxide regulation of human peripheral blood mononuclear cells: critical time dependence and selectivity for cytokine versus chemokine expression. J Immunol. https://doi.org/10.4049/jimmunol.171.9.4809

246. Bingisser RM, Tilbrook PA, Holt PG, Kees UR (1998) Macrophage-derived nitric oxide regulates $\mathrm{T}$ cell activation via reversible disruption of the Jak3/STAT5 signaling pathway. J Immunol. 160:5729-5734

247. Miyazaki T et al (1994) Functional activation of Jak1 and Jak3 by selective association with IL-2 receptor subunits. Science. https://doi.org/10.1126/science.7973659 (80)

248. Lu T et al (2011) Tumor-infiltrating myeloid cells induce tumor cell resistance to cytotoxic T cells in mice. J Clin Invest. https:// doi.org/10.1172/JCI45862

249. Kazak L, Cohen P (2020) Creatine metabolism: energy homeostasis, immunity and cancer biology. Nat Rev Endocrinol. https:// doi.org/10.1038/s41574-020-0365-5
250. Di Biase $\mathrm{S}$ et al (2019) Creatine uptake regulates CD8 T cell antitumor immunity. J Exp Med. https://doi.org/10.1084/jem. 20182044

251. He X, Lin H, Yuan L, Li B (2017) Combination therapy with $\mathrm{L}$-arginine and $\alpha$-PD-L1 antibody boosts immune response against osteosarcoma in immunocompetent mice. Cancer Biol Ther 18:94-100

252. De Jonge WJ et al (2002) Arginine deficiency affects early B cell maturation and lymphoid organ development in transgenic mice. J Clin Invest. https://doi.org/10.1172/JCI0216143

253. Kobayashi $\mathrm{T}$ et al (1998) Arginine enhances induction of $t$ helper 1 and $t$ helper 2 cytokine synthesis by peyer's patch $\alpha \beta$ $\mathrm{T}$ cells and antigen-specific mucosal immune response. Biosci Biotechnol Biochem. https://doi.org/10.1271/bbb.62.2334

254. Miret JJ et al (2019) Suppression of myeloid cell arginase activity leads to therapeutic response in a NSCLC mouse model by activating anti-tumor immunity. J Immunother Cancer. https://doi.org/10.1186/s40425-019-0504-5

255. Saini AS, Shenoy GN, Rath S, Bal V, George A (2014) Inducible nitric oxide synthase is a major intermediate in signaling pathways for the survival of plasma cells. Nat Immunol. https://doi.org/10.1038/ni.2806

256. Park KGM et al (1991) Stimulation of lymphocyte natural cytotoxicity by L-arginine. Lancet 337:645-646

257. Brittenden J et al (1994) L-Arginine stimulates host defenses in patients with breast cancer. Surgery 115:205-212

258. Reynolds JV et al (1988) Immunomodulatory mechanisms of arginine. Surgery 104:142-151

259. Lamas B et al (2012) Altered functions of natural killer cells in response to L-arginine availability. Cell Immunol 280:182-190

260. Oberlies $J$ et al (2009) Regulation of NK cell function by human granulocyte arginase. J Immunol. https://doi.org/10. 4049/jimmunol.0803523

261. Goh CC et al (2016) Hepatitis C virus-induced myeloid-derived suppressor cells suppress NK cell IFN- $\gamma$ production by altering cellular metabolism via arginase-1. J Immunol. https://doi.org/ 10.4049/jimmunol.1501881

262. Furuke K et al (1999) Human NK cells express endothelial nitric oxide synthase, and nitric oxide protects them from activation-induced cell death by regulating expression of TNF- $\alpha$. J Immunol 163:1473-1480

263. Filep JG, Baron C, Lachance S, Perreault C, Chan JSD (1996) Involvement of nitric oxide in target-cell lysis and DNA fragmentation induced by murine natural killer cells. Blood. https://doi.org/10.1182/blood.v87.12.5136.bloodjournal871 25136

264. Cifone MG et al (1994) Induction of the nitric oxide-synthesizing pathway in fresh and interleukin 2-cultured rat natural killer cells. Cell Immunol. https://doi.org/10.1006/cimm.1994.1215

265. Tate DJ et al (2008) Effect of arginase II on L-arginine depletion and cell growth in murine cell lines of renal cell carcinoma. J Hematol Oncol 1:14

266. Lemos H, Huang L, Prendergast GC, Mellor AL (2019) Immune control by amino acid catabolism during tumorigenesis and therapy. Nat Rev Cancer 1(19):162-175

267. Sica A, Schioppa T, Mantovani A, Allavena P (2006) Tumourassociated macrophages are a distinct M2 polarised population promoting tumour progression: potential targets of anti-cancer therapy. Eur J Cancer 42:717-727

268. Martinez FO, Gordon S, Locati M, Mantovani A (2006) Transcriptional profiling of the human monocyte-to-macrophage differentiation and polarization: new molecules and patterns of gene expression. J Immunol 177:7303-7311

269. Balkwill F, Charles KA, Mantovani A (2005) Smoldering and polarized inflammation in the initiation and promotion of malignant disease. Cancer Cell 7:211-217 
270. Chang CI, Liao JC, Kuo L (2001) Macrophage arginase promotes tumor cell growth and suppresses nitric oxide-mediated tumor cytotoxicity. Cancer Res 61:1100-1106

271. Davel LE et al (2002) Arginine metabolic pathways involved in the modulation of tumor-induced angiogenesis by macrophages. FEBS Lett 532:216-220

272. Gabrilovich DI et al (2007) The terminology issue for myeloidderived suppressor cells. Cancer Res 67:425

273. Gielen PR et al (2016) Elevated levels of polymorphonuclear myeloid-derived suppressor cells in patients with glioblastoma highly express S100A8/9 and arginase and suppress T cell function. Neuro Oncol 18:1253-1264

274. Montero AJ, Diaz-Montero CM, Kyriakopoulos CE, Bronte V, Mandruzzato S (2012) Myeloid-derived suppressor cells in cancer patients: a clinical perspective. J Immuno 35:107-115

275. Smith $C$ et al (2012) IDO is a nodal pathogenic driver of lung cancer and metastasis development. Cancer Discov 2:722-735

276. Sinha P, Clements VK, Ostrand-Rosenberg S (2005) Interleukin-13-regulated M2 macrophages in combination with myeloid suppressor cells block immune surveillance against metastasis. Cancer Res 65:11743-11751
277. Fultang L, Vardon A, De Santo C, Mussai F (2016) Molecular basis and current strategies of therapeutic arginine depletion for cancer. Internat J Cancer 139:501-509

278. Feun L, Savaraj N (2006) Pegylated arginine deiminase: a novel anticancer enzyme agent. Expert Opin Investig Drugs $15: 815-822$

279. Lowery MA et al (2017) A phase 1/1B trial of ADI-PEG 20 plus nab-paclitaxel and gemcitabine in patients with advanced pancreatic adenocarcinoma. Cancer 123:4556-4565

280. Hernandez CP et al (2010) Pegylated arginase I: a potential therapeutic approach in T-ALL. Blood 115:5214-5221

281. Steggerda SM et al (2017) Inhibition of arginase by CB-1158 blocks myeloid cell-mediated immune suppression in the tumor microenvironment. J Immunother Cancer 5:1-18

Publisher's Note Springer Nature remains neutral with regard to jurisdictional claims in published maps and institutional affiliations. 